\title{
Informality over the life-cycle
}

\author{
Julien Albertini* Anthony Terriau ${ }^{\dagger}$
}

June 18, 2019

\begin{abstract}
In developing countries, informality is mainly concentrated among younger and older workers and low-skilled workers. In this study, we propose a dual labor market theory that highlights how frictions and taxation in the formal sector and educational choices interact to shape the informality rate over the life-cycle. We develop a life-cycle model with search frictions, skill heterogeneities, and endogenous educational choices. We carry out a numerical analysis and show that our model reproduces remarkably well the life-cycle patterns of informality, non-employment, and formal employment in Argentina. We analyze several public policies and show that an educational grant reduces both informality and non-employment and may be fully financed by the extra tax revenues generated by the increase in formal employment and wages. Lowering taxes may achieve similar results but is detrimental to the government budget, despite increasing the base on which they are levied.
\end{abstract}

- JEL Classification: E26, J46, J64, O17

- Keywords: Informality; Search and matching; Life-cycle; Public policy; Laffer curve

${ }^{*}$ Univ Lyon, Université Lumière Lyon 2, GATE UMR 5824, F-69130 Ecully, France. Julien.Albertini@univ-lyon2.fr

†Univ Lyon, Université Lumière Lyon 2, GATE UMR 5824, F-69130 Ecully, France. anthony.terriau@univ-lyon2.fr 


\section{Introduction}

Informality is a major feature in most developing countries. For instance, the size of the shadow economy as a share of GDP ranges from $25 \%$ to $60 \%$ in Central and South America (Schneider and Enste, 2000; OECD/CIAT/IDB, 2016). A large body of research describes the characteristics of informal firms and workers in those developing countries. In particular, informal firms tend to be smaller, less productive, and pay lower wages (La Porta and Shleifer, 2008; Busso et al., 2012; La Porta and Shleifer, 2014; Meghir et al., 2015). As shown in Figure 1, the informality rate in Argentina is particularly high for younger and older workers, and for less-educated workers ${ }^{1}$. In addition, as shown in Panels (b) and (c), less-educated workers face a lower probability of finding a formal job and have a higher job separation rate than moreeducated workers. The job separation rate is represented by a U-shaped form, while the job finding rate is the opposite. These features naturally question the link between labor market search in the formal sector and the size of the informal sector. The originality of this study is in proposing a dual labor market theory that highlights how frictions and taxation in the formal sector, as well as educational choices interact to shape the informality rate over the life-cycle.

The notion of the dual labor market in developing countries is derived from the migration literature (Lewis, 1954; Todaro, 1969; Harris and Todaro, 1970; Fields, 1975). In these pioneering studies, urban wages are assumed to be initially higher than rural wages, and workers move from the rural sector to the urban sector until expected wages are equal across sectors. Following this literature, Zenou (2008) develops a dual labor market model in which the formal sector is characterized by search frictions, whereas the informal sector is competitive. In his framework, workers look for high-paid jobs in the formal sector that are time-consuming to find, or low-paid jobs in the informal sector that are available instantaneously. Although Zenou's framework provides some key insights into the nexus between frictions and informality in developing countries, it overlooks life-cycle aspects and skill heterogeneity. We argue that the age dynamics of workers and underlying educational decisions are crucial for understanding informality.

\footnotetext{
${ }^{1}$ The logistic regression provided in Appendix A confirms that the beginning and end of the career, and low education are significantly associated with the probability of working in the informal sector.
} 
Figure 1: Informality rate by skill level

(a) Informality rate

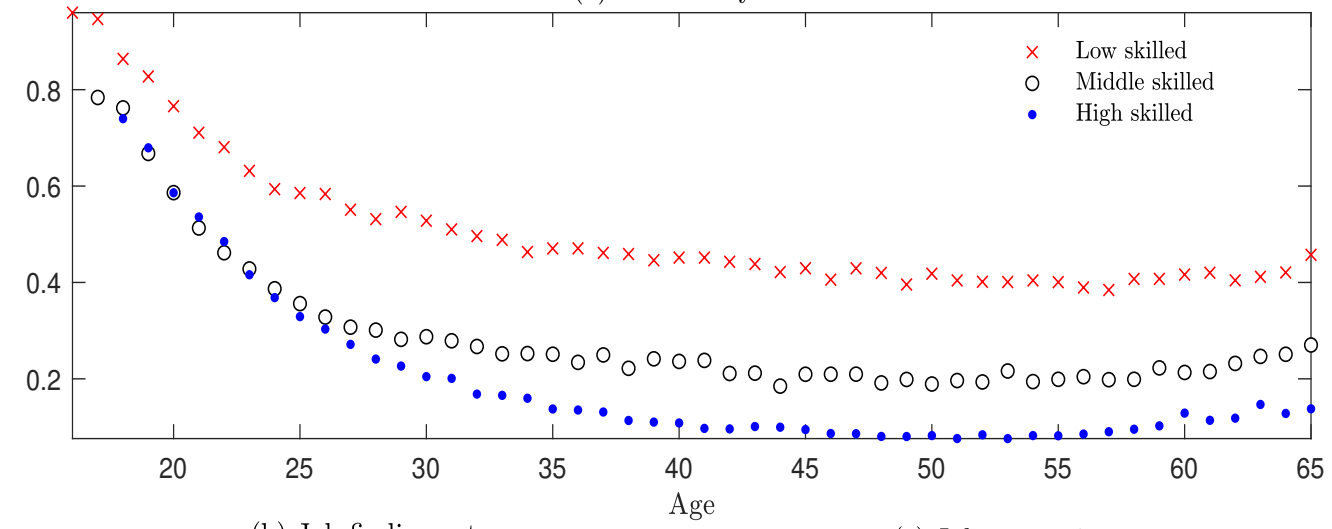

(b) Job finding rate

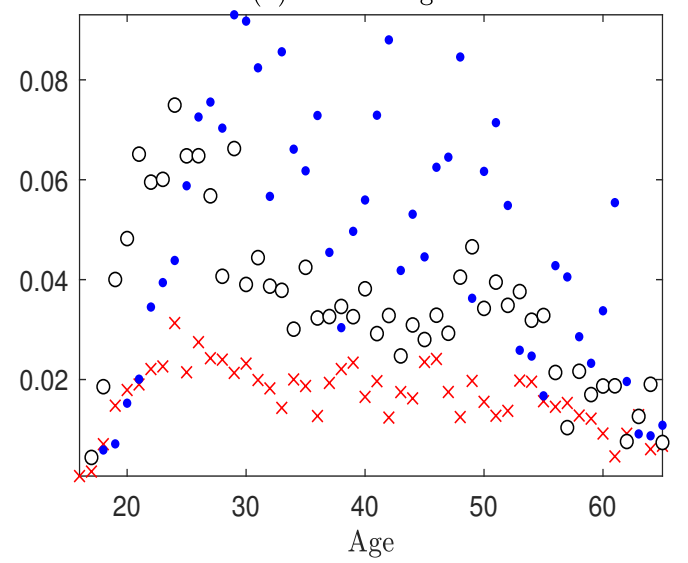

(c) Job separation rate

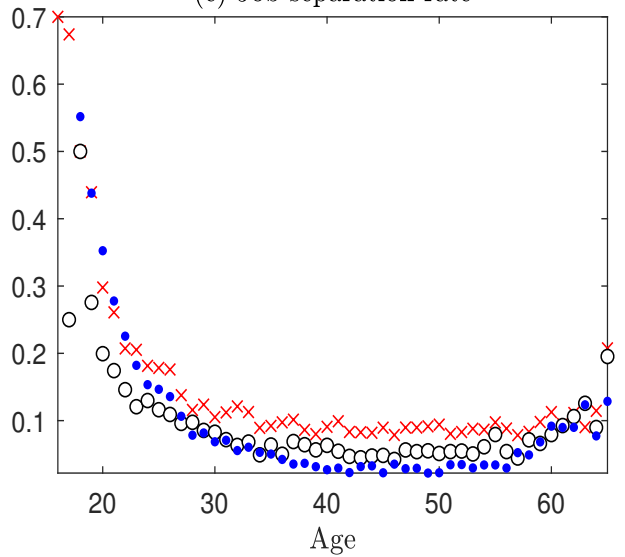

Source: Encuesta Permanente de Hogares (EPH), Argentina. Age: 16-65. The informality rate is calculated as the number of salaried employed workers in the informal sector / (salaried employed workers in the informal sector + salaried employed workers in the formal sector). Values are averaged over 2008Q1-2014Q4. Low skilled: less than high school. Middle skilled: high school. High skilled: college degree. See Appendix B for more details. The job finding rate and job separation rate are displayed at quarterly frequencies.

Indeed, Chéron et al. (2013) and Menzio et al. (2016) show that the probability of finding a job (implicitly, in the formal sector) varies considerably by age, thereby calling for an age-dependent framework with labor market frictions. Several papers document the particular dynamics of the informality rate over the life-cycle (Maloney, 1999; Bosch and Maloney, 2010; Narita, 2011; Garcia, 2015). The intuition is that at the beginning of the life-cycle, workers enter the labor market as non-employed and decide whether to work in the informal sector or engage in a formal job search process whose out- 
come is uncertain. Since low-educated workers and early school-leavers are more likely to be excluded from the formal sector, the informal sector becomes the only opportunity to escape non-employment. In addition, workers close to the retirement age are exposed to a higher risk of job loss and face more difficulties in finding a formal job (Chéron et al., 2013; Menzio et al., 2016), which causes them to turn toward the informal sector. The probability of finding (losing) a formal job is lower (higher) on both sides of the age spectrum, leading to a U-shaped form of the informality rate over the life-cycle.

To account for these patterns, we extend Zenou's framework by adopting a life-cycle approach with heterogeneous agents in age and educational attainment. In particular, we embed the age dynamic framework of Chéron et al. (2013) in which workers direct their search in the labor market. Workers are either non-employed or employed in one of the two sectors. At the beginning of their life-cycle, they decide how much they invest in schooling given their ex-ante heterogeneous ability to study. This educational choice gives rise to an endogenous skill composition of the labor force, which allows us to capture the interactions among frictions, participation decisions, and education. We solve and estimate the structural model on Argentinean data using an adaptive grid method. The model reproduces remarkably well the life-cycle patterns of the informality, non-employment, formal employment, and wage differentials across sectors and education in Argentina. We use the model to quantify the role of education, frictions, and taxation in shaping informality over the life-cycle. To do so, we investigate policy issues and discuss the most effective policy at fostering formal employment and lowering informality from a cost/benefit perspective.

As stated by Boeri et al. (2005), the informal sector has long been tolerated in developing countries. Most policies designed to fight informality consist of reinforcing the monitoring rate and repressing shadow employment (Bosch and Esteban-Pretel, 2012). The higher probability of detection and heavier cost of tax compliance lead to a rise in informal job destruction and a reduction in informal job creation. As a result, such policies reduce the informality rate at the expense of a rise in the non-employment rate. However, as underlined by Ulyssea (2010), no trade-off between informality and employment exists if we consider policies that increase the value of being formal instead of reducing the value of being informal. Most such policies are based on changes in regulation or taxation (Hopenhayn, 2004; Boeri et al., 2005; Satchi and Temple, 2009; Albrecht et al., 2009; Ulyssea, 2010; Charlot et al., 2015; Anand and Khera, 2016; Munkacsi and Saxegaard, 2017).

While an impressive number of studies have prescribed lowering taxation policies to cure - or at least curb-informal employment, little has been 
said about the fiscal costs of such reforms. Indeed, most of the debate has focused on the ability of labor market reforms to downsize the informal sector. From a political perspective, the shortfall in public revenue may impede the implementation of such reforms. Rocha et al. (2018) show that the tax reduction implemented in Brazil in the early 2010s succeeded in increasing formal employment. However, their cost/benefit analysis also suggests that formal employment gains do not compensate for tax reduction, leading to a negative net impact on tax revenues, even in the long run. Similar conclusions are drawn by Cruces et al. (2010), who undertake the social security reform in the mid-1990s in Argentina to show that the reduction in payroll taxes led to a sharp fall in tax collection, with limited effects on formal employment. These studies naturally question the long-term sustainability of tax-based reforms and call for a comprehensive investigation of their effects on tax revenues, employment, and informality.

In our study, we revisit the Laffer curve in a dual labor market framework. We examine whether it is possible to design a policy that reduces both informality and non-employment without exacerbating government deficits. We show that payroll tax cuts are effective at lowering informality, but are also likely to deteriorate the government budget despite increasing formal employment. The economy being located on the rising part of the Laffer curve, improving the fiscal surplus is only feasible through an increase in taxes. Tax cuts targeted at low-skilled jobs have lower detrimental effects on the fiscal budget, but involve a smaller reduction in informality. By reducing the incentive to study, such tax cuts shift the skill composition toward low-skilled workers, which offsets the job creation effects. We propose an alternative policy that consists of subsidizing education. We show that the employment and wage gains in the formal sector overcome the implementation costs of the reform. Such a subsidy affects the composition of the labor force by raising the share of high-skilled workers whose wages are higher. The fiscal cost of the subsidy is lower than that of a tax cut achieving a similar decline in the informality rate. In the long run, the cost is fully financed by the implied increase in tax revenues. This result is robust to alternative parameterizations of the marginal cost of education.

The remainder of the paper is organized as follows. The next section presents our data and provides empirical evidence on worker flows in Argentina. Section 3 describes the economic environment of the model and characterizes the equilibrium. A numerical analysis of the model is presented in Section 4. We then consider different policies in Section 5. Finally, Section 6 summarizes our findings and concludes. 


\section{Empirical analysis}

\section{$2.1 \quad$ Data}

We take advantage of the EPH, a household survey in Argentina that provides information about the employment state (employed, unemployed, or out of the labor force) and social contributions paid by employees. Among employed workers, we distinguish those who pay social contributions (formal workers) from those who do not (informal workers). Our sample consists of 337,979 individuals aged $16-65^{2}$.

\subsection{Transition probabilities}

The EPH is based on $2-2-2$ periodicity. Individuals are interviewed in two consecutive quarters $(q$ and $q+1)$, are not interviewed in the following two quarters $(q+2$ and $q+3)$, and then are re-interviewed for two consecutive quarters $(q+4$ and $q+5)$. We use the consecutive quarterly interviews provided by each individual to compute the transition probabilities across employment states $^{3}$ (formal employment, informal employment, and nonemployment).

Table 1 displays the transition matrix, which reveals some interesting patterns. The probability of switching from non-employment to informal employment $(7.68 \%)$ is more than three times as high as the transition probability from non-employment to formal employment (2.38\%). This suggests that it is much easier to find a job in the informal sector than in the formal sector, which is consistent with Zenou's framework. Another interesting point is that transitions from informal employment to formal employment (11.60\%) are much larger than transitions in the opposite direction (4.64\%), suggesting a form of segmented labor market. It may be tempting to think that such transitions are the result of on-the-job search decisions. However, transitions between the formal and informal sectors must be interpreted with caution. For example, in the data, a worker can move from the informal sector to the formal sector for at least three reasons. First, employment status is based on the main job. If an employee holds several jobs at the same time (a formal job and an informal job) and if the outcomes from the formal job (informal job) increase (decrease) quarter over quarter, he or she can be con-

\footnotetext{
${ }^{2}$ In Argentina, the minimum age for employment is 16 . Individuals can benefit from a basic pension and an additional pension (social insurance) at age 65 for men and 60 for women with at least 30 years of service. Source: Argentine Ministry of Labor

${ }^{3}$ Throughout the paper, we exclude self-employed workers and focus on salaried workers.
} 
sidered as switching from the informal sector to the formal sector, although this transition is "spurious" and does not reflect on-the-job search. Second, transitions from informal employment to formal employment may be due to the formalization of the current employer. This cannot be counted as a standard job change. Third, as we only have information on labor force status at a quarterly frequency, some switches from informal to formal jobs may occur through non-employment between two observation periods. This is all the more likely since informal jobs are often precarious ${ }^{4}$. All these arguments suggest that "true" direct transitions from informal jobs to formal jobs are relatively scarce. Thus, we follow Zenou (2008) and Albrecht et al. (2009) by considering that no direct transitions occur across sectors. Another interesting question is whether there is on-the-job search within each sector. To identify job-to-job transitions in a given sector, we use information on job duration. Workers having at least one quarter of seniority within the same firm are considered as "non-movers," while workers reporting less than three months of service in the company are classified as "movers." Few job-to-job transitions occur in the formal sector $(0.77 \%)$ compared with the informal sector $(5.38 \%)$. As job-to-job transitions in the formal sector are scarce and as we assume that the informal sector is perfectly competitive, we do not consider on-the-job search in our model.

Table 1: Transition probabilities

\begin{tabular}{|c|c|c|c|}
\hline State $t+1$ & $\begin{array}{c}\text { Formal } \\
\text { Employed }\end{array}$ & $\begin{array}{c}\text { Informal } \\
\text { Employed }\end{array}$ & Non-employed \\
\hline Formal & 91.69 & 4.64 & 3.63 \\
\hline Employed & $(0.77)$ & & \\
\hline $\begin{array}{l}\text { Informal } \\
\text { Employed }\end{array}$ & 11.60 & $\begin{array}{l}68.81 \\
(5.38)\end{array}$ & 19.59 \\
\hline Non-Employed & 2.38 & 7.68 & 89.93 \\
\hline $\begin{array}{l}\text { Source: EPH } 2008-201 \\
\text { Note: Job-to-job transi } \\
\text { Sample: Individuals ag } \\
\text { Number of observation }\end{array}$ & $\begin{array}{l}\text { ions in brack } \\
\text { d 16-65 year } \\
\text { (different in }\end{array}$ & ts & \\
\hline
\end{tabular}

\footnotetext{
${ }^{4}$ The average job duration is 2.5 times lower than in the formal sector. Nearly a quarter of informal jobs last less than three months.
} 


\section{Model}

The model is grounded on the work of Zenou (2008) in which a formal and an informal sector coexist in the labor market. The former is characterized by search frictions, whereas the latter is competitive. We extend his framework to a life-cycle version with educational decisions and endogenous separations.

\subsection{Heterogeneity}

Workers are heterogeneous according to age $t$ and educational attainment a. Furthermore, workers employed in the formal sector are heterogeneous in their specific productivity level $\varepsilon$. In each period, the oldest generation of workers retires and is replaced by a younger generation of the same size such that the population of workers is constant. The new generation enters the labor market at an age that depends on educational attainment. We consider a life-cycle $t=t_{0}, \ldots, T$ with $t_{0}=16$ and $T=65$. In the formal sector, search is directed to age $t$ and education $a$, both of which are assumed to be perfectly observable. Consistent with Figure 1, we consider three levels of education $a \in \Omega_{a}$ and $\Omega_{a}=\left\{a_{1}, a_{2}, a_{3}\right\}$ for low, middle, and high respectively. The productivity of employed workers grows with age at a deterministic rate to capture human capital accumulation over the life-cycle.

\subsection{Worker flows}

Let $u_{t, a}$ and $v_{t, a}$ be respectively the number of unemployed workers and number of vacant jobs in the formal sector. The number of hires per unit of time in the formal sector is given by the matching function:

$$
M_{t, a}=M\left(u_{t, a}, v_{t, a}\right)
$$

where the function $M($.$) is increasing in both arguments but exhibits de-$ creasing marginal products to each input. Let $\theta_{t, a}=v_{t, a} / u_{t, a}$ be labor market tightness. Since the matching function is assumed to be homogeneous of degree one in its two arguments, we have $M\left(u_{t, a}, v_{t, a}\right)=M\left(1, v_{t, a} / u_{t, a}\right) u_{t, a}=$ $M\left(1, \theta_{t, a}\right) u_{t, a}$. A vacancy is filled with probability $q_{t, a}$ and a non-employed worker has a probability $\theta_{t, a} q_{t, a}$ of finding a formal job. It is useful to rewrite these probabilities as follows:

$$
\begin{aligned}
q_{t, a} & =M\left(u_{t, a}, v_{t, a}\right) / v_{t, a}=M\left(1 / \theta_{t, a}, 1\right) \\
\theta_{t, a} q_{t, a} & =M\left(u_{t, a}, v_{t, a}\right) / u_{t, a}=M\left(1, \theta_{t, a}\right)
\end{aligned}
$$


Figure 2 describes the timing of events ${ }^{5}$. [1] At the beginning of age $t$, a proportion $\delta_{t, a}$ of employment inherited from the previous age is destroyed. This proportion corresponds to individuals that retire before the retirement age for the basic pension ${ }^{6}$. [2] Idiosyncratic productivity shocks $\varepsilon^{\prime}$ are drawn from the distribution $G($.$) defined on [0, \bar{\varepsilon}]$. [3] If job-specific productivity $\varepsilon$ falls below an endogenous threshold $\underline{\varepsilon}_{t, a}$, the job is destroyed. The endogenous job destruction rate is given by $G\left(\underline{\varepsilon}_{t, a}\right)$ and the total separation rate is $\delta_{t, a}+\left(1-\delta_{t, a}\right) G\left(\underline{\varepsilon}_{t, a}\right)$. [4] Formal employment at age $t$ is evaluated. It has two components: new matches and matches inherited from the previous age. New matches are formed at the end of the previous age and contribute to age $t$ employment. New matches are also subjected to idiosyncratic shocks. [5] Non-employed workers decide whether to move to the informal sector or rest unemployed and search for a formal job. [6] New workers enter the labor force depending on their level of educational attainment. They become part of the job seeker pool defined in [7]. Lastly, the number of matches is determined at the end of the period [8].

We denote by $N_{t, a}$ the labor force of age $t$ and education $a$. Formally, we have

$$
N_{t, a}=N_{t-1, a}+\frac{N_{t, a}^{n e w}}{1-H(a)}
$$

where $N_{t, a}^{\text {new }}$ is exogenously given and depicted in Appendix C. $H(a)$ is the distribution function of workers over education levels defined later. The mass of individuals in each skill category is equal to one at age $T, N_{T, a}=1$.

Among the $N_{t, a}$ individuals, $L_{t, a}^{F}$ work in the formal sector, $L_{t, a}^{I}$ work in the informal sector, and the remaining proportion $u_{t, a}^{F}$ are formal non-employed:

$$
u_{t, a}=N_{t, a}-L_{t, a}^{F}-L_{t, a}^{I}
$$

Formal employment is given by the following law of motion:

$$
L_{t, a}^{F}=L_{t-1, a}^{F}\left(1-\delta_{t, a}\right)\left(1-G\left(\underline{\varepsilon}_{t, a}\right)\right)+\theta_{t-1, a} q_{t-1, a}\left(1-G\left(\underline{\varepsilon}_{t, a}\right)\right) u_{t-1, a}
$$

\footnotetext{
${ }^{5}$ Section 3.8 explains the timing of the educational decision.

${ }^{6}$ Special arrangements allow for early retirement from the age of 50 . To be consistent with the observed data, individuals that retire before the age of 65 ( 60 for women) are counted as non-employed. We take this rate as given from the data and choose not to model endogenous retirement decisions for the sake of clarity. Our data indicate that a significant proportion of formally employed workers leave their job for retirement purposes after age 50. This outflow impacts the shape of the aggregate time series substantially. To reproduce the life-cycle profile observed in the data, we then include this separation rate in our model as an exogenous variable. In alternative calibrations, we consider that $\delta_{t, a}=0, \forall t$. This leaves the main message of the study unchanged.
} 
Figure 2: Timing of events

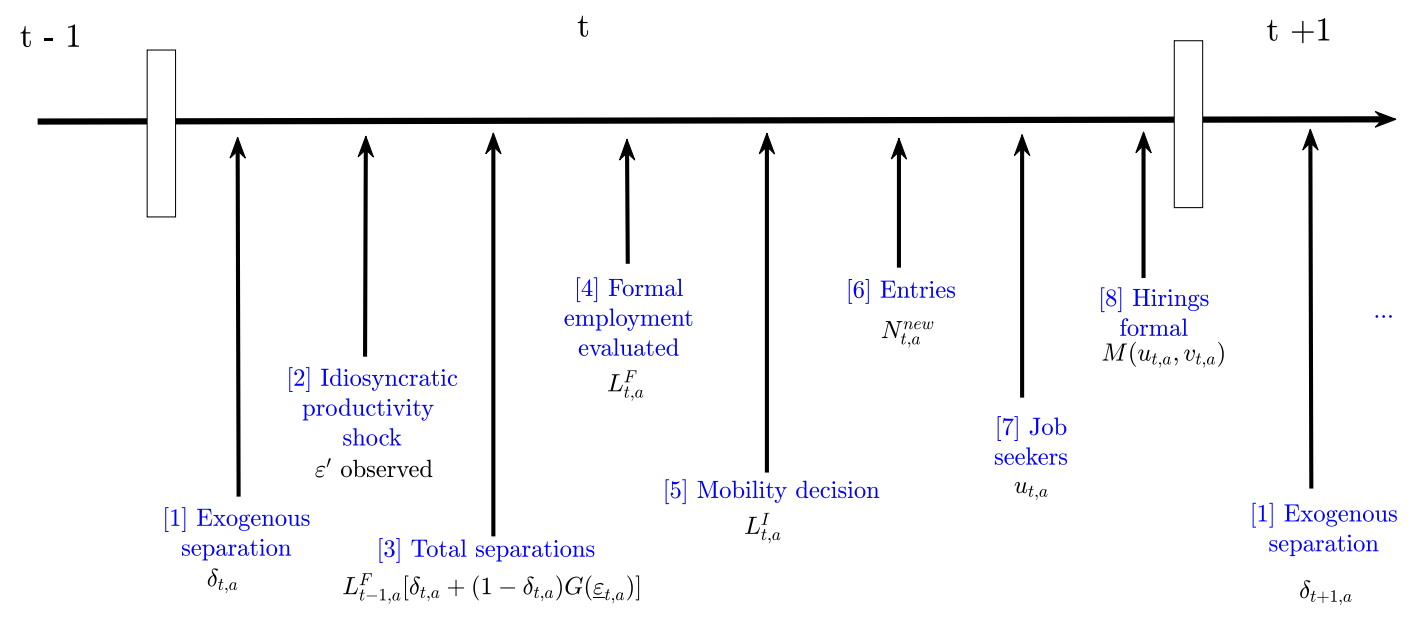

Matches formed during the previous period $(t-1)$ are counted in formal employment at age $t$. Informal employment is determined after formal employment, meaning that $L_{t, a}^{I} \leq N_{t, a}-L_{t, a}^{F}$. Furthermore, we assume that students cannot work in either of the sectors and that individuals who have left school can no longer switch from one skill to another.

Lastly, using the density function of workers over education levels, the aggregate mass of workers is

$$
N_{t}=\int N_{t, a} h(a) d a
$$

\subsection{Value functions}

\subsubsection{Informal sector}

We assume that the informal sector is perfectly competitive. $F\left(L_{t, a}^{I}\right)$ denotes the production function. Labor $L_{t, a}^{I}$ is the only input in the production function. As is standard, we assume that $F^{\prime}\left(L_{t, a}^{I}\right)>0$ and $F^{\prime \prime}\left(L_{t, a}^{I}\right) \leq$ 0 . Informal workers and employers do not pay taxes. The informal wage, denoted by $w_{t, a}^{I}$, is equal to the marginal product of labor:

$$
w_{t, a}^{I}=F^{\prime}\left(L_{t, a}^{I}\right)
$$

Since the informal labor market is characterized by full employment, workers who lose their informal job can find another informal job instantaneously. Consequently, the expected value of employment in the informal sector $\left(E_{t, a}^{I}\right)$ 
can be expressed as the sum of the present values (discounted at rate $\beta$ ) of all future informal wages, that is,

$$
E_{t, a}^{I}=\sum_{j=t}^{T-1} \beta^{j-t} w_{j, a}^{I}=\sum_{j=t}^{T-1} \beta^{j-t} F^{\prime}\left(L_{j, a}^{I}\right)
$$

\subsubsection{Formal sector}

Let $w_{t, a, \varepsilon}^{F}$ be the formal wage and $\tau_{w}$ the tax rate on workers' wages. The expected value of employment $\left(E_{t, a, \varepsilon}^{F}\right)$ is given by

$$
\begin{aligned}
E_{t, a, \varepsilon}^{F}= & w_{t, a, \varepsilon}^{F}\left(1-\tau_{w}\right)+\beta \delta_{t, a} U_{t+1, a} \\
& +\beta\left(1-\delta_{t, a}\right)\left[\int_{0}^{\underline{\varepsilon}_{t+1, a}} U_{t+1, a} d G\left(\varepsilon^{\prime}\right)+\int_{\underline{\varepsilon}_{t+1, a}}^{\bar{\varepsilon}} E_{t+1, a, \varepsilon^{\prime}}^{F} d G\left(\varepsilon^{\prime}\right)\right]
\end{aligned}
$$

The present value of a formal job corresponds to the wage net of social security contributions. In each period, the employed worker can separate from the firm exogenously at rate $\delta_{t, a}$ or endogenously at rate $\left(1-\delta_{t, a}\right) G\left(\underline{\varepsilon}_{t, a}\right)$. In both cases, the worker becomes non-employed.

All non-employed workers engaged in a search process have the following present value:

$$
\begin{aligned}
U_{t, a}= & b+\beta \theta_{t, a} q_{t, a}\left[\int_{0}^{\underline{\varepsilon}_{t+1, a}} U_{t+1, a} d G\left(\varepsilon^{\prime}\right)+\int_{\underline{\varepsilon}_{t+1, a}}^{\bar{\varepsilon}} E_{t+1, a, \varepsilon^{\prime}}^{F} d G\left(\varepsilon^{\prime}\right)\right] \\
& +\beta\left(1-\theta_{t, a} q_{t, a}\right) U_{t+1, a}
\end{aligned}
$$

A non-employed worker enjoys, at age $t$, a return equal to home production $b^{7}$. In the next period, he or she may find a formal job with probability $\theta_{t, a} q_{t, a}$ or remain non-employed.

The expected value of a filled job $\left(J_{t, a, \varepsilon}\right)$ with a worker at age $t$ and education $a$ is defined by

$$
\begin{aligned}
J_{t, a, \varepsilon}= & y_{t, a, \varepsilon}-\Gamma-w_{t, a, \varepsilon}^{F}\left(1+\tau_{f}\right)+\beta \delta_{t, a} \max _{t, a} V_{t, a} \\
& +\beta\left(1-\delta_{t, a}\right)\left[\int_{0}^{\underline{\varepsilon}_{t+1, a}} \max _{t, a} V_{t, a} d G\left(\varepsilon^{\prime}\right)+\int_{\underline{\varepsilon}_{t+1, a}}^{\bar{\varepsilon}} J_{t+1, a, \varepsilon^{\prime}} d G\left(\varepsilon^{\prime}\right)\right]
\end{aligned}
$$

${ }^{7}$ As underlined by Bosch and Esteban-Pretel (2015), unemployment benefit systems do not exist or are limited in developing countries. According to our calculations and the estimates of Iturriza et al. (2011), only $5 \%$ of the unemployed receive unemployment benefits in Argentina. We consider that $b$ reflects only home production and leisure but not unemployment benefits. It is then similar across workers with different skills. 
where $y_{t, a, \varepsilon}$ is the skill and age-dependent productivity and $\Gamma$ is a fixed cost that corresponds to the operating costs as in Rotemberg (2008). If a separation occurs, the job becomes vacant and the firm decides to which ability and age its search is directed.

Any firm is free to open a job vacancy directed toward a worker of age $t$ and education $a$, involving a recruitment $\operatorname{cost} c_{a}$. The vacant job at time $t$ is filled at time $t+1$ with a probability $q_{t, a}$. Each employer pays a tax $\tau_{f}$, proportional to the worker's wage. The present value of a vacancy $\left(V_{t, a}\right)$ satisfies

$$
\begin{aligned}
V_{t, a}= & -c_{a}+\beta q_{t, a}\left[\int_{0}^{\underline{\varepsilon}_{t+1, a}} \max _{t, a} V_{t, a} d G\left(\varepsilon^{\prime}\right)+\int_{\underline{\varepsilon}_{t+1, a}}^{\bar{\varepsilon}} J_{t+1, a, \varepsilon^{\prime}} d G\left(\varepsilon^{\prime}\right)\right] \\
& +\beta\left(1-q_{t, a}\right) \max _{t, a} V_{t, a}
\end{aligned}
$$

\subsection{Decision rules}

New firms enter the labor market and open job vacancies until the expected surplus from a vacant job is equal to zero. This free-entry condition is written as

$$
V_{t, a}=0 \quad \forall t, a
$$

The job destruction rule is determined through the endogenous-specific productivity threshold. The job becomes unprofitable if the specific productivity component falls below the threshold $\underline{\varepsilon}_{t, a}$. It is better to dismiss the worker if $\varepsilon<\underline{\varepsilon}_{t, a}$. This rule is written as

$$
J_{t, a, \underline{\varepsilon}_{t, a}}=0 \quad \forall t, a
$$

\subsection{Wage determination}

Let $\alpha_{a} \in[0,1]$ be the relative bargaining power of workers, considered as identical across ages but different across skill levels. In each period, the worker's surplus $\left(E_{t, a, \varepsilon}^{F}-U_{t, a}\right)$ and the firm's surplus $\left(J_{t, a, \varepsilon}\right)$ are shared according to a Nash bargaining process. Formally,

$$
w_{t, a, \varepsilon}^{F}=\arg \max _{w_{t, a, \varepsilon}^{F}}\left(E_{t, a, \varepsilon}^{F}-U_{t, a}\right)^{\alpha_{a}}\left(J_{t, a, \varepsilon}\right)^{1-\alpha_{a}}
$$

The optimality condition of the above problem is

$$
\left(1-\alpha_{a}\right)\left(1+\tau_{f}\right)\left(E_{t, a, \varepsilon}^{F}-U_{t, a}^{F}\right)=\alpha_{a}\left(1+\tau_{w}\right) J_{t, a, \varepsilon}^{F}
$$


Using Equations (10) to (13), the wage is given by

$$
w_{t, a, \varepsilon}^{F}=\frac{\alpha_{a}}{1+\tau_{f}}\left(y_{t, a, \varepsilon}-\Gamma+c_{a} \theta_{t, a}\right)+\frac{1-\alpha_{a}}{1-\tau_{w}} b
$$

\subsection{Job creation and job destruction}

Using the value functions (13) and (12), wage rate (18), free-entry condition (14), and job destruction condition (15), we obtain the following job creation condition $\forall t, a$ :

$$
\frac{c_{a}}{q_{t, a}}=\beta\left(1-\alpha_{a}\right) \int_{\underline{\varepsilon}_{t+1, a}}^{\bar{\varepsilon}} y_{t+1, a, \varepsilon^{\prime}}-y_{t+1, a, \underline{\varepsilon}_{t+1, a}} d G\left(\varepsilon^{\prime}\right)
$$

At the equilibrium, the average cost of recruiting a worker of age $t$ and education $a$ (term on the left-hand side) is equal to the expected value of a filled job (term on the right-hand side).

The threshold value of the productivity component is determined using Equation (15), substituting Equation (18) into (12), and setting $\varepsilon=\underline{\varepsilon}_{t, a}$. After some algebra, we obtain

$$
0=y_{t, a, \underline{\varepsilon}_{t, a}}-\Gamma-\frac{1+\tau_{f}}{1-\tau_{w}} b-\frac{\alpha_{a}}{1-\alpha_{a}} c_{a} \theta_{t, a}+\frac{1-\delta_{t, a}}{1-\alpha_{a}} \frac{c_{a}}{q_{t, a}}
$$

\subsection{Mobility condition}

All non-employed workers decide whether they search for a job in the frictional formal labor market or accept a job in the competitive informal labor market. Workers move toward the informal sector until the expected utility of searching for a formal job is equal to the expected utility of informal employment. At the equilibrium, non-employed individuals are indifferent between looking for a job in the formal sector and being employed in the informal sector. Thus,

$$
U_{t, a}=E_{t, a}^{I}
$$

At the equilibrium, informally employed workers and non-employed workers waiting for formal job offers coexist. Using Equation (9) and (21), we obtain the following equilibrium mobility condition:

$$
U_{t, a}=F^{\prime}\left(L_{t, a}^{I}\right)+\beta E_{t+1, a}^{I}
$$




\subsection{Educational choice}

Individuals are characterized by the ability level $x$ that measures the aptitude for formal studies. Abilities are distributed according to a Pareto distribution $A($.$) over the interval [\underline{x}, \bar{x}]$. Before entering the labor market, individuals choose their optimal education level $a_{x}^{\star} \in \Omega_{a}$, given

- The expected value of non-employment by the level of education $\left(U_{t_{a}, a}\right)$, at the expected time of labor market entry $\left(t_{a}\right)$ that depends on the educational attainment chosen,

- The total cost of education denoted by $\kappa_{x, a}$ that includes:

- The direct cost of education (tuition fees) equal to $\gamma_{a}$,

- The cost of effort $\Phi(x)$ related to an additional period of education, which is assumed to be decreasing, convex, and twice differentiable $\left(\Phi^{\prime}(x)<0\right.$ and $\left.\Phi^{\prime \prime}(x)<0\right)$,

$$
\kappa_{x, a}=\gamma_{a}+\Phi(x)
$$

- The (dis)utility derived from education $z_{a}^{8}$.

At the beginning of the life-cycle $\left(t_{0}=16\right)$, individuals decide whether to enter the labor market as low-skilled non-employed workers or start an education program. We denote by $t_{a}=\left\{t_{1}, t_{2}, t_{3}\right\}$ the expected duration of educational attainment $a$. If an individual decides not to study, his or her ability is low $\left(a=a_{1}\right)$ and his or her expected utility at age $t=16$ is $U_{t_{1}+1, a_{1}}$. We then impose $t_{1}=15$. On the contrary, if the individual undertakes a high school or college degree, he or she expects to enter the labor market at age $t_{i}+1>t_{1}+1, i=2,3^{9}$. The present expected utility when entering the labor market is $U_{t_{a}+1, a}$. Given ability level $x$, the optimal educational decision is

\footnotetext{
${ }^{8} \mathrm{We}$ assume that this depends on the education degree because the time spent on leisure or the commuting cost can be different.

${ }^{9}$ It should be noted that $1+t_{a}$ is the expected age of entry in the labor market and not the effective age of entry. The former is exogenously given. In fact, individuals decide their educational attainment at time $t=16$ based on the average duration of studies. At the time of making such a decision, they cannot know the exact duration of a high school or college degree. The effective duration can be shorter or longer depending on the educational program, ability of the individual, and so on. We then assume that educational decisions are based on the expected entry date $t_{a}+1$, whereas the effective entry date is given by $N_{t, a}^{n e w}$.
} 
the solution of the following program:

$$
a_{x}^{\star}=\underset{a \in \Omega_{a}}{\arg \max } \mathbb{1}_{a \neq a_{1}} \sum_{t=1}^{t_{a}} \beta^{t-1}\left(z_{a}-\kappa_{x, a}\right)+\beta^{t_{a}} U_{t_{a}+1, a}
$$

where $\mathbb{1}_{a \neq a_{1}}$ is an indicator variable taking the value one if educational attainment is middle or high. Individuals choose to pursue schooling until the marginal gain of an extra degree of education becomes lower than the marginal cost associated with the additional degree, that is,

$$
\begin{aligned}
& \underbrace{\beta^{t_{i}} U\left(t_{i}+1, a_{i}\right)-\beta^{t_{i-1}} U\left(t_{i-1}+1, a_{i-1}\right)}_{\begin{array}{c}
\text { Marginal gain of an } \\
\text { additional degree of education }
\end{array}} \\
& <\underbrace{\sum_{t=1}^{t_{i}} \beta^{t-1}\left(\kappa_{x, a_{i}}-z_{a_{i}}\right)-\sum_{t=1}^{t_{i-1}} \beta^{t-1}\left(\kappa_{x, a_{i-1}}-z_{a_{i-1}}\right)}_{\begin{array}{c}
\text { Marginal cost of an } \\
\text { additional degree of education }
\end{array}}
\end{aligned}
$$

The above condition defines the threshold ability $\tilde{x}_{i}, i=1,2$, below which the individual prefers not to pursue an additional degree of education. This constraint binds at $\tilde{x}_{i}$ such that an individual with ability $\tilde{x}_{i}$ is indifferent between education degrees $i$ and $i-1$. The threshold ability $\tilde{x}_{i}$ provides the mass of workers in each skill category $H\left(a_{i}\right)$. Given that $\tilde{x}_{3}=\bar{x}$, we have

$$
H\left(a_{i}\right)=\int_{\underline{x}}^{\tilde{x}_{i}} d A(x), \quad i=1,2,3
$$

\subsection{Government budget}

The government collects taxes from formal workers and funds education. We distinguish two costs related to education: (1) $\Lambda$ : the public cost of education, which corresponds to the salary of teachers, public infrastructure, and some running costs. (2) $s$ : the educational grant given to students. The fiscal surplus is then defined as

$$
F S=\left(\tau_{w}+\tau_{f}\right) \sum_{t=1}^{T} \sum_{a \in \Omega_{a}} L_{t, a}^{F} \int_{\underline{\varepsilon}_{t, a}}^{\bar{\varepsilon}} w_{t, a, \varepsilon}^{F} d \varepsilon-(\Lambda+s) \sum_{t=1}^{T} \sum_{a \in \Omega_{a}} \mathbb{1}_{a \neq a_{1}} N_{t, a}^{\text {new }}
$$

The government budget is balanced with lump-sum transfers $\pi$ :

$$
\pi=F S
$$




\subsection{Definition of the equilibrium and solution method}

Definition 1. For every age $t \in\left[t_{0}, T\right]$, and for (a) the $\delta_{t, a}$ and $N_{t, a}^{\text {new }}$ processes, (b) an initial condition on labor market aggregates $L_{0, a}^{F}, L_{0, a}^{I}, u_{0, a}$, $N_{0, a}$ and $N_{0}$, (c) a terminal condition on quantities $q_{T, a}, \theta_{T, a}, \underline{\varepsilon}_{T, a}$ and on value functions $E_{T, a}^{I}, E_{T, a, \varepsilon}^{F}, U_{T, a}$, and $J_{T, a, \varepsilon}$, the equilibrium is a sequence of (i) quantities $q_{t, a}, \theta_{t, a}, \underline{\varepsilon}_{t, a}$; (ii) value functions $E_{t, a}^{I}, E_{t, a, \varepsilon}^{F}, U_{t, a}$, and $J_{t, a, \varepsilon}$; (iii) wages $w_{t, a, \varepsilon}^{F}$ and $w_{t, a}^{I}$; (iv) labor market aggregates $L_{t, a}^{F}, L_{t, a}^{I}, u_{t, a}, N_{t, a}$ and $N_{t}$; (v) optimal educational decisions $a_{x}^{\star}$; (vi) the stationary distribution of workers across skills $H\left(a_{i}\right)$; and (vii) fiscal surplus FS and lump-sum transfer $\pi$ satisfying the following conditions:

(i) $q_{t, a}, \theta_{t, a}$, and $\underline{\varepsilon}_{t, a}$ are the solutions of the job finding rate (3), job creation condition (19), and job destruction condition (20), respectively

(ii) $E_{t, a}^{I}, E_{t, a, \varepsilon}^{F}, U_{t, a}$, and $J_{t, a, \varepsilon}$ solve the Bellman equations (9) to (12)

(iii) $w_{t, a}^{I}$ and $w_{t, a, \varepsilon}^{F}$ satisfy (8) and (18)

(iv) $L_{t, a}^{F}, L_{t, a}^{I}, u_{t, a}^{F}, N_{t, a}$, and $N_{t}$ are the stationary solutions of (4) to (7) and (22)

(v) $a_{x}^{\star}$ solves the educational choice program (23)

(vi) $H\left(a_{i}\right)$ satisfies the stationary distribution (25)

(vii) FS and $\pi$ satisfy the government budget defined by (26) and (27)

As the presented model has no analytical solution, we use numerical methods to solve it. The algorithm aims to find the life-cycle trajectory of the variables given an initial condition for the state (backward) variables and a terminal condition for the control (forward) variables, and taking into account a set of exogenous processes (labor market entries and exits). We take advantage of the block-recursive aspect of the model that allows casting the algorithm into two sub-routines. We first solve for the paths of the forward variables $(i)$ to $($ iii $)$. Second, we obtain the backward variables' trajectories (iv) using the law of motion of labor market aggregates. Third, given the trajectories of the backward and forward variables, we solve $(v)$ to $(v i i)$. The supplementary appendix describes the algorithm. 


\section{Numerical analysis}

\subsection{Functional forms}

- Productivity in the formal sector can be written as

$$
\log \left(y_{t, a, \varepsilon}\right)=\lambda_{a}^{F} \log (t)+\log (\varepsilon)
$$

This form illustrates how productivity grows with age at a deterministic rate $\lambda_{a}^{F}$. Provided that $\lambda_{a}^{F}<1$, the experience profile of wage is concave. Several studies introduce similar functional forms to proxy for the experience effect on productivity (Burdett et al., 2011; Bagger et al., 2014; Blundell et al., 2016). We then capture the main features of the experience effects on productivity and wages.

- Production in the informal sector is given by the following function:

$$
\log \left(F\left(L_{t, a}^{I}\right)\right)=\lambda_{a}^{I} \log (t)+\sigma \log \left(L_{t, a}^{I}\right)
$$

As for the formal sector, we consider human capital accumulation through experience over the life-cycle.

- We consider a standard Cobb-Douglas matching function:

$$
M\left(u_{t, a}, v_{t, a}\right)=\mu_{a} u_{t, a}^{\eta} v_{t, a}^{1-\eta}
$$

where $\mu_{a}$ stands for the matching efficiency and $\eta$ the elasticity of the matching function with regard to unemployment.

- The education cost depends on the ability level $x$ and is given by the following function:

$$
\Phi(x)=\phi_{0} x^{\phi_{1}}
$$

where $\phi_{0}$ scales the cost of education and $\phi_{1}$ the curvature of the function.

- Abilities $x$ are given by the Pareto distribution over the support $x \in$ $[\underline{x}, \bar{x}]$ :

$$
A(x)=\frac{1-(\underline{x} / x)^{d}}{1-(\underline{x} / \bar{x})^{d}}
$$

- Idiosyncratic productivity $\varepsilon$ is given by a uniform distribution over the support $\varepsilon \in[0, \bar{\varepsilon}]$ :

$$
G(\varepsilon)=\frac{\varepsilon-0}{\bar{\varepsilon}-0}
$$




\subsection{Calibration and estimation strategy}

We first set the value of some of the parameters based on external sources. We then use a minimization routine to estimate the remaining parameters in such a way that the model matches several empirical targets.

\subsubsection{Parameter set externally.}

We consider quarterly frequencies and a life-cycle horizon of 50 years with $t_{0}=16$ and $T=65$. The discount factor is set to 0.92 , giving an annual real interest rate of about 9\% (Garcia-Cicco et al., 2010). Social security contributions represent $42 \%$ of employees' gross remuneration. Employees' tax rate is $17 \%$, while employers' tax rate is about $25 \%,{ }^{10}$ which are the values considered for $\tau_{w}$ and $\tau_{f}$, respectively. Using the EPH, we calculate the exogenous (time-varying) separation rate $\delta_{t, a}$ related to early retirement. In line with Chéron and Terriau (2018), we consider that abilities for education are distributed according to a truncated Pareto distribution over the support $[1,2]$ with the parameter $d=1^{11}$.

According to the Center for Study of Education in Argentina, the annual public cost of education per student is just under $30 \%$ of the average formal wage per year, which involves $\Lambda=0.29$. To calculate the total public cost, we use the entries (Appendix C) from the EPH survey to determine the average number of years for the schooling degrees $a_{2}$ and $a_{3}$. The survey documents whether individuals are students or not (employed or non-employed), as well as their schooling degree. This allows us to estimate the average time spent in studying for individuals that enter the labor market after a high school degree or a college degree. A high school degree corresponds to two additional years of education with respect to low-skilled workers, and a college degree represents six years of studies on average. We then assume that $t_{2}=17$ and $t_{3}=21$. Public universities in Argentina cover around $80 \%$ of students. Tuition fees are almost zero. We then assume that $\gamma_{x}=0$. Lastly, we use the observed entry rates, reported in Appendix C, to determine the sequence of $N_{t, a}^{n e w}$. Table 2 summarizes the calibrated parameters.

\footnotetext{
${ }^{10} \mathrm{~A}$ total employer social security rate of $27 \%$ is required from companies whose main activity consists of commerce or rendering services, provided their annual sales exceed 48 million Argentine pesos. All other companies are subject to the $23 \%$ rate. We take the average of these two rates. See Appendix D.

${ }^{11}$ We impose these values for the Pareto distribution but estimate the educational cost function. Changing the support does not affect the quantitative implications of the model since it simply scales the range of ability.
} 
Table 2: Calibrated parameters

\begin{tabular}{lcc}
\hline Parameter & Symbol & Value \\
\hline Discount factor & $\beta$ & 0.92 \\
Expected entry age for low-skilled & $t_{1}$ & 15 \\
Expected entry age for middle-skilled & $t_{2}$ & 17 \\
Expected entry age for high-skilled & $t_{3}$ & 21 \\
Final age & $T$ & 65 \\
Support of the idiosyncratic productivity & {$[0, \bar{\varepsilon}]$} & {$[0,1]$} \\
Employees' social security contributions & $\tau_{w}$ & $17 \%$ \\
Employers' social security contributions & $\tau_{f}$ & $25 \%$ \\
Subsidy to education & $s$ & 0 \\
Support for the Pareto distribution & {$[\underline{x}, \bar{x}]$} & {$[1,2]$} \\
Shape of the Pareto distribution & $d$ & 1.0 \\
Annual public cost of education per student & $\Lambda$ & 0.29 \\
\hline
\end{tabular}

\subsubsection{Parameter set internally}

The remaining parameters are estimated. Our goal is to reproduce the following life-cycle series: (i) the informality rate, (ii) the formal employment rate, (iii) the non-employment rate, (iv) the job finding rate, (v) the job separation rate, (vi) the wage premium between formal and informal workers, and (vii) the wage differentials between high-skilled and middle-skilled workers, and between high-skilled and low-skilled workers. (i) to (vi) are divided into skill categories (low, middle, and high), which amounts to 18 life-cycle series. (vii) are divided into the formal and informal sectors, which amounts to four life-cycle series. In total, we have $I=22$ life-cycle series. The set of observations at each age is given by $\left\{\boldsymbol{Y}_{1, t}, \boldsymbol{Y}_{2, t}, \ldots, \boldsymbol{Y}_{I, t}\right\}_{t=t_{0}}^{T}$. We introduce two additional moments: the proportions of low- and middle-skilled workers. Let $\boldsymbol{M}=\left\{h\left(a_{1}\right), h\left(a_{2}\right)\right\}$ be the vector of moments related to the distribution of workers across skills. Table 3 summarizes the targets.

Two types of parameters are estimated: skill-dependent parameters and parameters common to all skill categories. We assume that neither the matching technology $(\eta)$ nor the production technology of the informal sector $(\sigma)$ differs among the skill categories. The value of non-market activity is also similar among workers with different skill levels, as it does not include unemployment benefits ${ }^{12}$. The education cost function summarized by

\footnotetext{
${ }^{12}$ The average unemployment insurance replacement rate is $25 \%$. However, only $5 \%$ of unemployed workers receive unemployment benefits (Source: EPH). We then consider that $b$ corresponds to the value of leisure and home production and does not include unemployment benefits.
} 
Table 3: Targets for the estimation

\begin{tabular}{|c|c|}
\hline Variable & Symbol \\
\hline Informality rate & $\frac{L_{t, a}^{I}}{L_{t, a}^{I}+L_{t, a}^{F}}$ \\
\hline Formal employment rate & $\frac{L_{t, a}^{F}}{N_{t, a}}$ \\
\hline Non-employment rate & $\frac{u_{t, a}}{N_{t, a}}$ \\
\hline Job finding rate & $\theta_{t, a} q_{t, a}\left(1-G\left(\underline{\varepsilon}_{t, a}\right)\right)$ \\
\hline Job separation rate & $\delta_{t, a}+\left(1-\delta_{t, a}\right) G\left(\underline{\varepsilon}_{t, a}\right)$ \\
\hline Wage premium (formal/informal) & $\frac{w_{t, a}^{F}\left(1-\tau_{w}\right)}{w_{t, a}^{I}}$ \\
\hline Wage differential (high/i) & $\frac{w_{t, h i g h}^{j}}{w_{t, i}^{j}} \quad i=\{$ mid, low $\}, \quad j=F, I$ \\
\hline Proportion of low- and high-educated workers & $\frac{\sum_{t} N_{t, a}}{\sum_{t} N_{t}}$ \\
\hline
\end{tabular}

$\phi_{0}$ and $\phi_{1}$ is by definition similar for all individuals. Lastly, the operating (fixed) cost $\Gamma$ is also assumed to be similar across the different job types. All the remaining parameters are assumed to be skill-dependent. The set of structural parameters is given by

$$
\Theta=\left\{\eta, b, \sigma, \phi_{0}, \phi_{1}, \Gamma, \lambda_{a}^{F}, \lambda_{a}^{I}, \mu_{a}, c_{a}, \alpha_{a}, z_{a}\right\}, \quad a=1,2,3
$$

The strategy consists of finding the value of the parameters that best fits the life-cycle series and the proportions of workers across skill categories observed in the data ${ }^{13}$. Formally, the optimization problem is written as

$$
\begin{aligned}
\hat{\Theta} & =\underset{\Theta}{\arg \min } \mathcal{R}(\Theta) \\
\mathcal{R}(\Theta) & =\sum_{t=1}^{T} \sum_{i=1}^{I}\left(\boldsymbol{Y}_{i, t}^{d}-\boldsymbol{Y}_{i, t}^{m}(\Theta)\right)^{2}+\mathbb{1}_{x} \sum_{n=1}^{2}\left(\boldsymbol{M}_{n}^{d}-\boldsymbol{M}_{n}^{m}(\Theta)\right)^{2}
\end{aligned}
$$

where $\boldsymbol{Y}_{i, t}^{m}(\Theta)$ are the simulated life-cycle series (i)-(vii), $\boldsymbol{M}_{n}^{m}(\Theta)$ are the simulated moments, and $\mathbb{1}_{x}$ an indicator function taking zero if the sum of squared differences between $\boldsymbol{M}_{n}^{d}$ and $\boldsymbol{M}_{n}^{m}(\Theta)$ is lower than $0.1 \%$ and infinity

\footnotetext{
${ }^{13}$ All targeted series are built using EPH over the period 2008Q1-2014Q4.
} 
otherwise $^{14}$. We use an adaptive grid to solve the problem $(28)^{15}$. This consists of constructing a wide multidimensional grid covering the space of the parameter values and refining the grid at each iteration around the values most likely to match the target.

\subsection{Estimation results}

\subsubsection{Matching the life-cycle profile}

How well does the model capture the salient features of the data? Figures 3 to 5 show the life-cycle profile of the variables from the model's simulations against their empirical counterparts.

While the model is simple, it produces a consistent U-shape of the informality rate over the life-cycle. At the beginning of the life-cycle, individuals are either located in the informal sector or are non-employed. As shown by Figure 4, low-skilled workers face greater difficulties in finding a formal job and are more likely to separate from formal employment. As a consequence, the aggregate youth employment rate (up to age 24) in the formal sector barely exceeds $30 \%$ and the non-employment rate is high.

For middle-age workers, the job finding rate increases and job separation rate declines sharply, a characteristic well captured in our model thanks to the educational decisions and rise in average productivity of the formal sector. The educational decisions involve a composition effect in which the delayed entry of middle- and high-skilled workers further increases the job finding rate. The non-employment rate falls more slowly for high-skilled workers at the beginning of the life-cycle since they are counted as non-employed during their period of education and reaches lower values thereafter. In addition, the aggregate formal employment rate increases abruptly until age 50, which reduces the informality rate. These patterns are well reproduced by our model. While the model overestimates the decline in non-employment, it still produces a descent U-shape and the correct gap between the skill groups.

\footnotetext{
${ }^{14}$ We introduce this indicator function because the number of moments involved in the life-cycle series is several times larger than that of the proportions of workers across the skill categories $(22 \times T \times 4$ quarters $=4400$ versus 2 moments. As we want the model to be able to replicate accurately the distribution of workers across skills, we set $\mathbb{1}_{x}=+\infty$ if the second term is higher than an arbitrary threshold. Doing so, the algorithm discards all parameter values that do not match the proportions accurately.

${ }^{15}$ See the supplementary appendix for details on the solution technique and estimation procedure.
} 
Figure 3: Labor market stocks

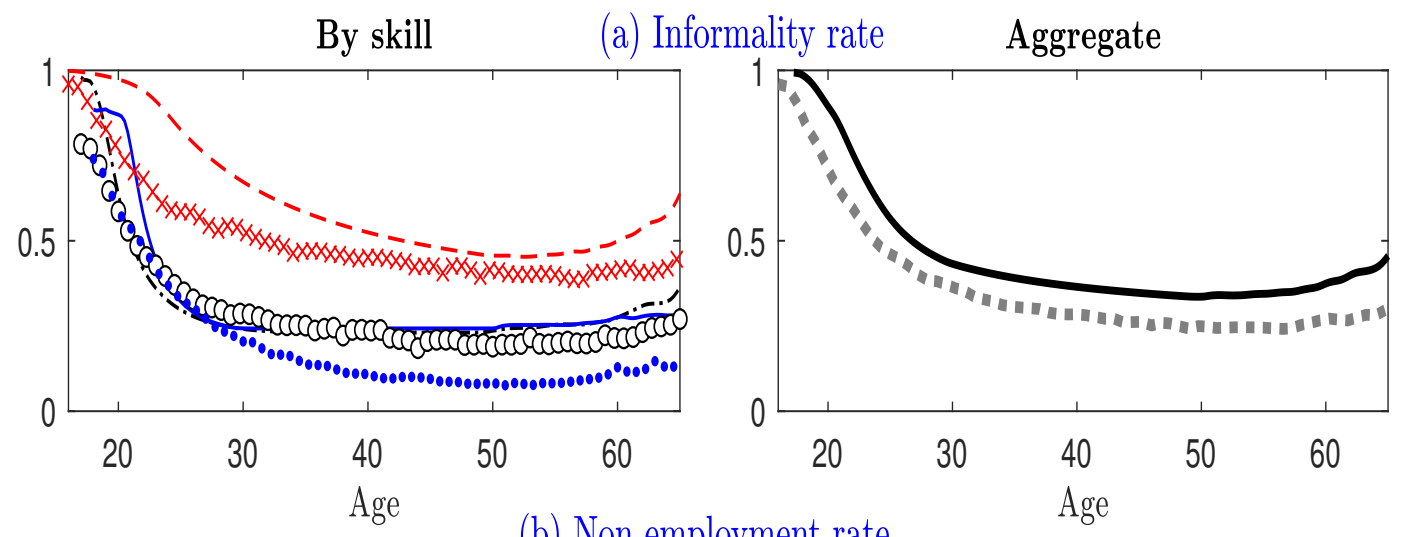

(b) Non employment rate
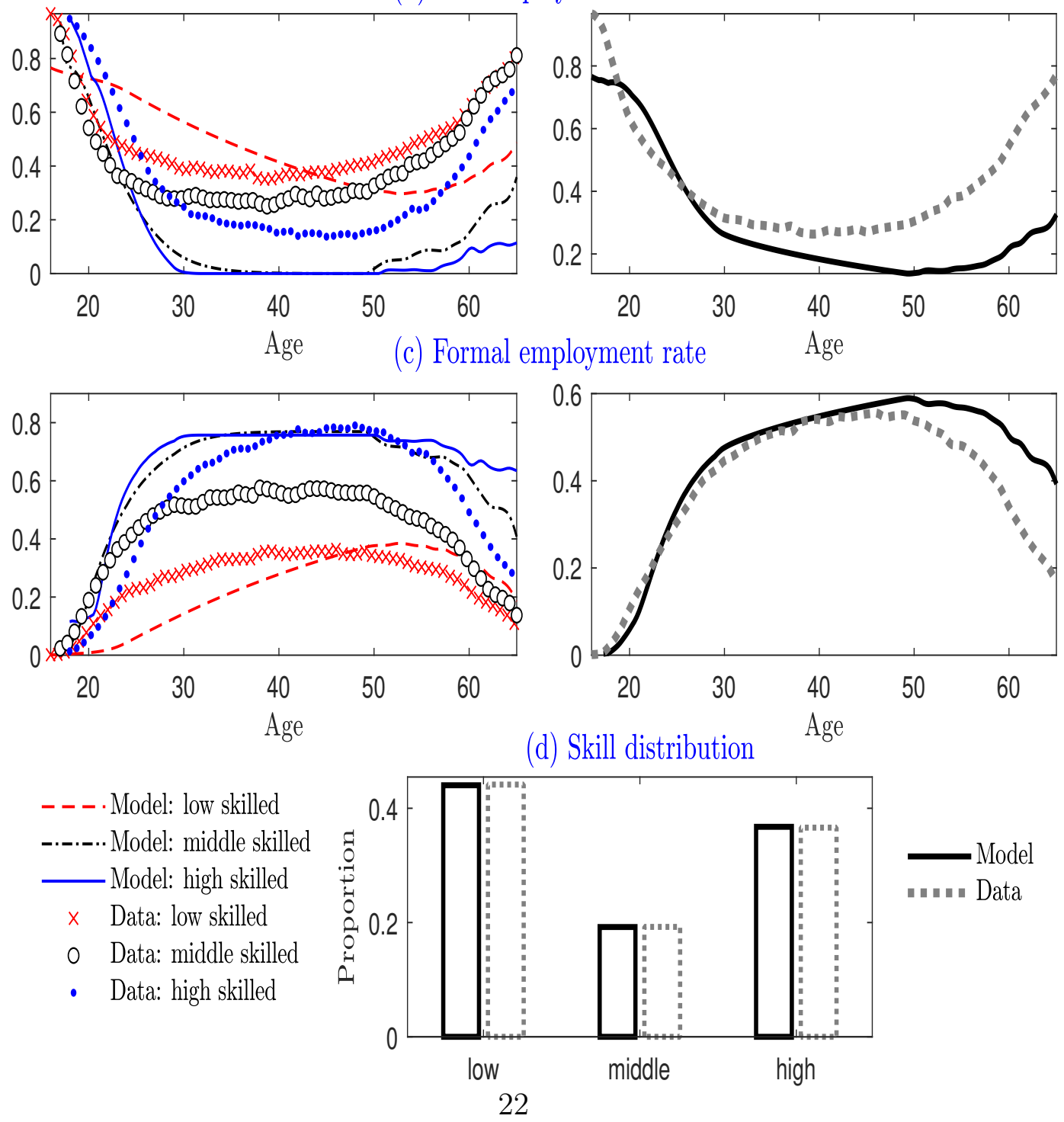
At the end of the life-cycle, the expected duration of a match becomes lower. The fall in the job finding rate and increasing number of exits from the labor market cause a sizable decline in formal employment. This in turn involves a rebound in informality and non-employment. Although our model slightly overestimates the aggregate informality rate, it captures well its lifecycle profile. The model can also reproduce the dynamics of informality by education level throughout the life-cycle, although it encounters some difficulties in matching the smooth declining profile of the job finding rate. Lastly, the model matches accurately the proportion of workers in each skill category.

\section{Figure 4: Labor market flows}

(a) Job finding rate
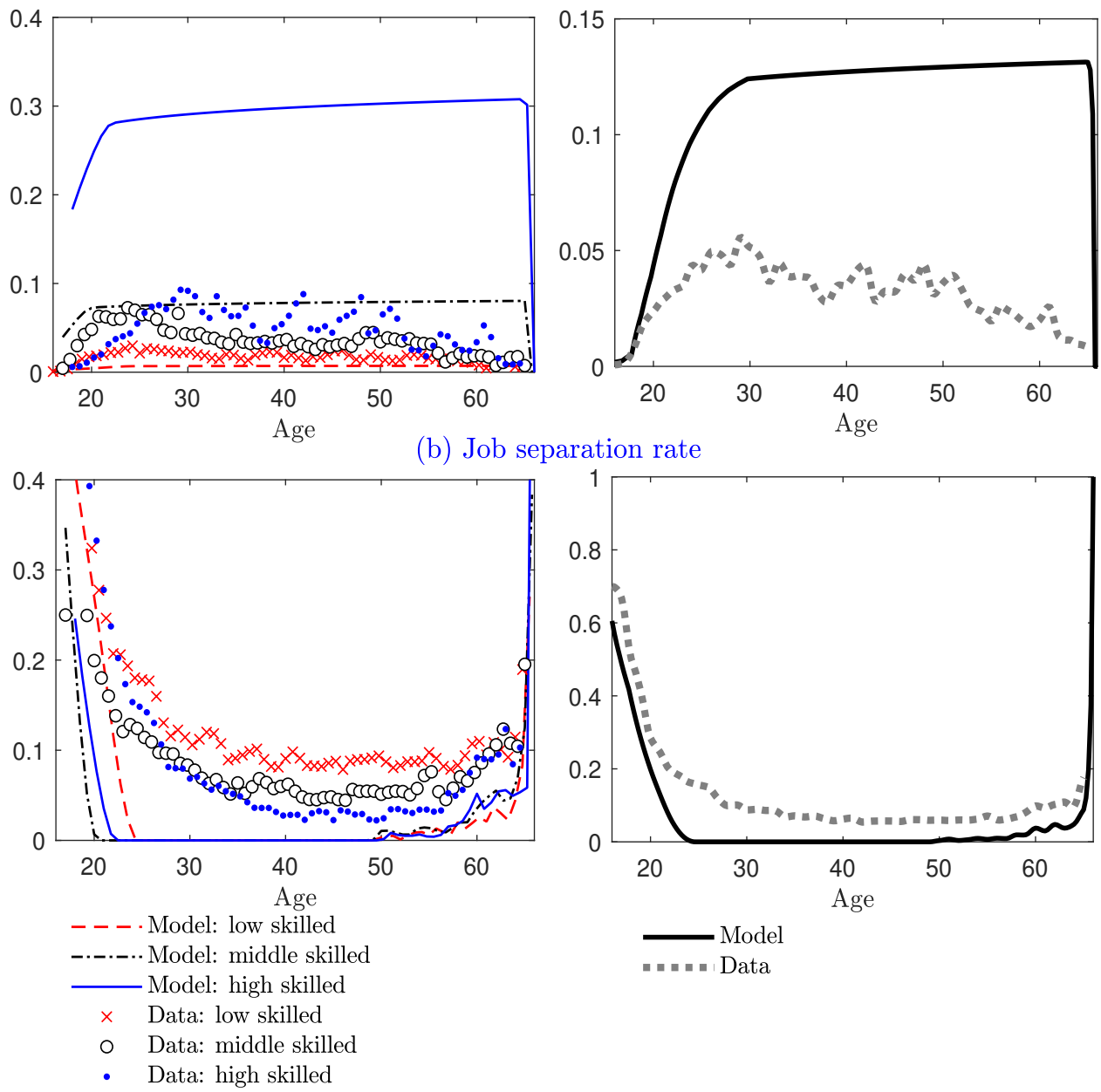

Quarterly values displayed 
Figure 5: Wage differentials

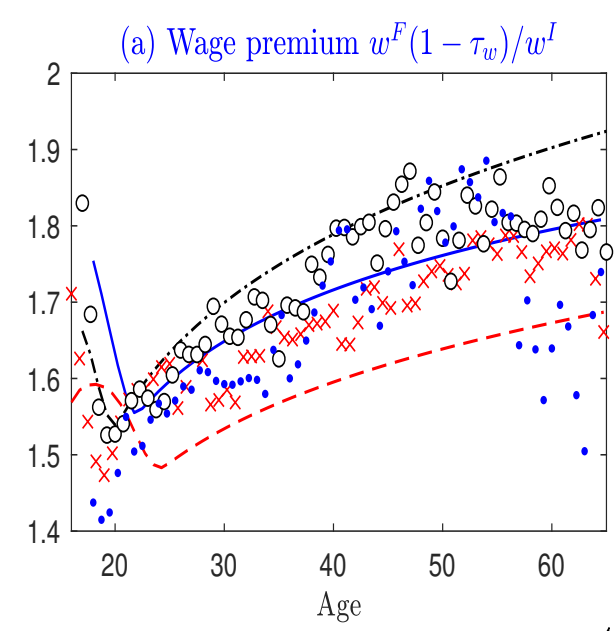

(b) Wage differential (formal)

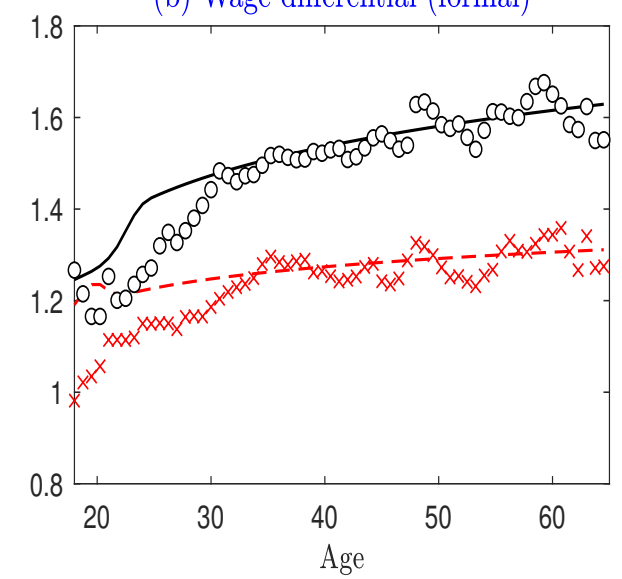

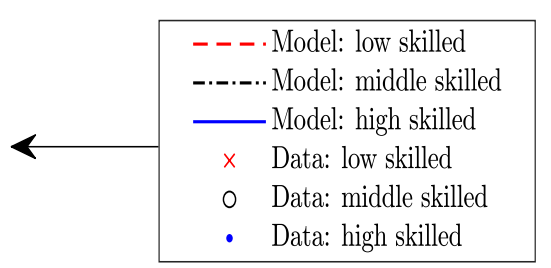

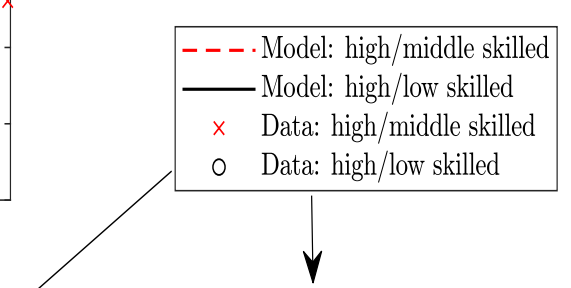

(c) Wage differential (informal)

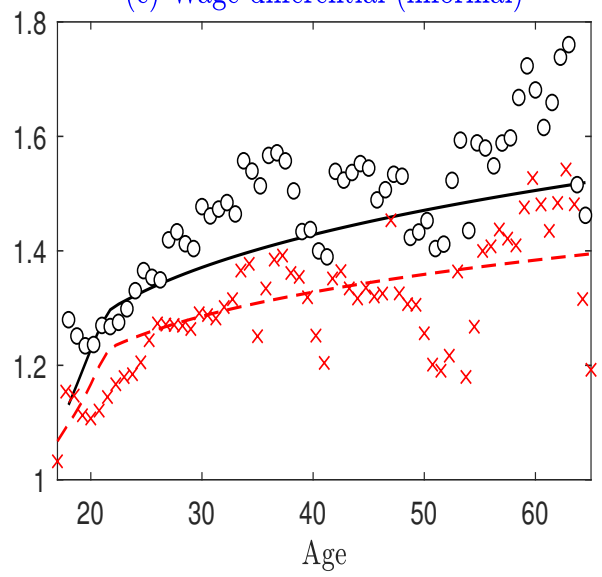

Net wage (minus employees' social security contributions). Data: hourly wage rate, controlled for individual characteristics.

A crucial point concerns the ability of our model to reproduce the wage differential across sectors and skill levels throughout the life-cycle. They are important targets, as they directly affect educational choices and mobility decisions. Figure 4 displays the wage differential produced by the model and those estimated by the EPH. As shown in Panel (a), the net hourly wage premium between the formal and informal sectors ranges between 1.4 to 1.9, all other things being equal. It increases and displays a concave form over the life-cycle. The highest premium concerns workers with a middle educational attainment, and the lowest belongs to low-skilled workers. The 
model matches the observed evolution of the wage premium across education levels very well.

Panels (b) and (c) display the wage differentials between the skill levels in the formal and informal sectors, respectively. The ratios are similar across sectors. Indeed, in both, the wage differentials between high- and low-skilled workers range between 1.2 at the beginning of the life-cycle and 1.7 at the end. The one between high- and middle-skilled workers starts at a ratio of 1 at age 16 and reaches about 1.4 at age 65 . As for the wage premium shown in Panel (a), the pace at which the wage differentials grow is higher for younger than for older workers, suggesting diminishing returns to human capital and experience. All the measures of wage differentials across skills are close to those found in the data. Hence, our model reproduces remarkably well the wage differentials across sectors and levels of education.

\subsubsection{Estimated parameters}

Table 4 shows the parameter values implied by the estimation procedure. Matching efficiency $(\mu)$ ranges from 0.01 for low-skilled workers to 0.27 for high-skilled workers, while the vacancy posting cost is relatively similar across skill levels. These parameters contribute to generate job finding rates that are increasing with education. The estimated value for worker bargaining power $\left(\alpha_{a}\right)$ ranges from 0.38 for low-skilled workers to 0.57 for high-skilled workers. The most-educated employees generate a higher surplus but can also extract a larger share of this surplus. The elasticity of the matching function with regard to unemployment $(\eta)$ is 0.83 , which means that less than $20 \%$ of the variations in the number of hirings are accounted for by changes in the number of vacancies. Note that $\alpha_{a}$ and $\eta$ differ significantly irrespective of the original level of education. This means that the estimation does not support the Hosios condition $\left(\alpha_{a}=\eta\right)$ and inefficiencies come from the search externalities. In other words, the competitive equilibrium and social planer are distinct equilibrium allocations, even in the absence of proportional taxes (laissez-faire economy).

The parameter governing the rate at which productivity increases in the formal sector $\left(\lambda_{a}^{F}\right)$ is about 1.4 times larger for high-skilled workers than for low-skilled workers, and 1.14 times larger than that for middle-skilled workers. Furthermore, these parameters are twice as large in the formal sector than in the informal sector for low- and high-skilled workers, and about five times larger for middle-skilled workers.

The value of non-market activities (b) is 0.38 , which represents $39 \%$ of the average wage of formal employees. The utility derived from a high school education $z_{2}$ is also found to be 0.38. By contrast, the utility associated 
with a college program $z_{3}$ is smaller $(0.24)$. This finding is consistent with those of Frenette $(2004,2006)$, who shows that colleges are generally farther away from the family home than high schools, which entails extra costs and reduces utility. With $\phi_{0}=0.32$ and $\phi_{1}=-4.17$, the estimated education cost function is decreasing and strongly convex in ability $x$. The operating cost $\Gamma$ represent $36 \%$ of the average wage

Table 4: Estimated parameters and targets

\begin{tabular}{lcccc}
\hline Parameter & Symbol & Low & Middle & High \\
\hline Matching efficiency & $\mu$ & 0.01 & 0.09 & 0.27 \\
Vacancy posting cost & $c$ & 0.13 & 0.15 & 0.10 \\
Workers' bargaining power & $\alpha$ & 0.38 & 0.45 & 0.57 \\
Productivity (formal sector) & $\lambda^{F}$ & 0.17 & 0.21 & 0.24 \\
Productivity (informal sector) & $\lambda^{I}$ & 0.08 & 0.04 & 0.12 \\
Utility derived from education & $z$ & & 0.38 & 0.24 \\
\hline & & & Common \\
& & & 0.38 & \\
\hline Value of non-market activities & $b$ & & 0.83 & \\
Elast. matching w.r.t. vacancies & $\eta$ & & 0.09 & \\
Curvature of the production & $\sigma$ & & 0.32 & \\
$\quad$ function (informal sector) & \multicolumn{3}{c}{-4.17} & \\
Scale of educational cost & $\phi_{0}$ & & 0.35 & \\
Curvature of education cost & $\phi_{1}$ & & \\
Operating cost & $\Gamma$ & &
\end{tabular}

\section{$5 \quad$ Labor market policies}

What are the formal employment gains of lowering payroll taxes and subsidizing educational attainment? What are the associated fiscal costs? How much of informality is accounted for by labor taxation and the disutility associated with education? To answer these questions, we conduct two experiments. First, we use different policy instruments to lower the informality rate by one percentage point and compare the implied fiscal costs. Second, we vary all policy instruments over a broad range of values and investigate their impact on labor market outcomes. 


\subsection{Lowering the informality rate by one percentage point}

In this first experiment, to lower the informality rate by one percentage point, we adjust employers' tax $\operatorname{rate}^{16}\left(\tau_{f}\right)$ or the subsidy to education $(s)$ in isolation.

Table 5 summarizes the aggregate consequences of the policies and Figure 6 depicts the life-cycle effects. We first discuss the effects of a reduction in the payroll tax rate. A one percentage point lower informality rate reduces $\tau_{f}$ by around 3.5 percentage points. The implied elasticity of informality and formal employment with respect to tax is consistent with empirical studies conducted in Colombia (Fernández and Villar, 2017). They estimate that the tax reform in Columbia, namely a reduction in payroll taxes by 14 percentage points, involves a decline in informality by four percentage points, a ratio identical to ours (3.5/1). Lowering labor taxation enhances the joint surplus of matches, which increases job creation and curbs job destruction in the formal sector, thereby reducing the informality rate. Enhancing labor market prospects in the formal sector, this policy also increases the returns of education. As shown in Panel (f) of Figure 6, this translates into a reduction in the proportion of low- and middle-skilled workers and an increase in the share of high-skilled workers. Consequently, as shown in Panels (a) and (d), the effects of such a policy are particularly large once high-skilled workers enter the labor market (i.e., between the ages 20 and 30). The formal employment gains become smaller for middle-age workers. The job separation rate of mid-career workers is initially close to zero, which limits the effects of the policy. At the end of the life-cycle, as the benchmark job separation is growing, the reduction in payroll taxes plays a stronger role in lowering job destruction, which explains why the aggregate effects are higher for people approaching retirement.

The second experiment consists of subsidizing education. The educational grant $(s)$ needed to generate a drop of one percentage point in the informality rate amounts to $1 \%$ of the average wage in the formal sector (before implementation). Such a subsidy drives the non-employment rate below the level reached by the tax policies ( -1.2 percentage points vs. -0.9 percentage points) and involves larger employment gains in the formal sector $(+1.5$ percentage points vs. +1.1 percentage points). As shown in Panel (f) of Figure 6, the composition of the labor force polarizes more strongly. Diminishing the cost

\footnotetext{
${ }^{16}$ As the surplus of the match (and thus taxes) is shared between the worker and firm, the aggregate effects of a decrease in $\tau_{w}$ or $\tau_{f}$ are identical. As most policies conducted in developing countries target employers' tax rates, we focus on the impact of a change in $\tau_{f}$.
} 
of education, this policy provides powerful incentives to pursue long-term studies. As a result, the skill distribution shifts to the right. The share of low-skilled workers drops by almost four percentage points, while the proportion of high-skilled individuals increases by five percentage points. At the beginning of the life-cycle, the subsidy-based policy generates a spike in non-employment and informality because individuals who choose to pursue their studies are counted as non-employed during their additional years of education. The effect of this policy is maximal at age 30, once all high-skilled workers enter the labor market. In the mid-career period, the impact of the policy weakens. First, the horizon effect involves a smaller increase in the surplus from formal employment as the worker becomes closer to retirement. Second, the impact of the policy on the job separation rate is larger at the two extremities of the age spectrum. As a result, the formal employment gains increase slightly at the end of the life-cycle.

Table 5: Policy reforms: lower informality rate by one percentage point

\begin{tabular}{|c|c|c|c|}
\hline Policy & $\begin{array}{c}\text { Benchmark } \\
\text { economy }\end{array}$ & $\begin{array}{c}\text { Firms' } \\
\text { tax } \\
\tau_{f}\end{array}$ & $\begin{array}{c}\text { Subsidy to } \\
\text { education } \\
s\end{array}$ \\
\hline$\tau_{f}$ & 25.0 & 21.5 & 25.0 \\
\hline$s^{1}$ & 0.0 & 0.0 & 1.0 \\
\hline Informality rate & 44.8 & 43.8 & 43.8 \\
\hline Non-employment rate & 28.2 & 27.3 & 27.0 \\
\hline Formal employment rate & 46.6 & 47.7 & 48.1 \\
\hline Job finding rate & 12.5 & 13.3 & 13.8 \\
\hline Job separation rate & 3.7 & 2.8 & 3.1 \\
\hline Total wage ${ }^{2}$ & 100.0 & 105.4 & 104.7 \\
\hline Fiscal surplus $^{2}$ & 100.0 & 95.7 & 103.7 \\
\hline Ex-ante fiscal surplus ${ }^{3}$ & 100.0 & 90.6 & 98.4 \\
\hline
\end{tabular}

1: The subsidy is expressed as a percentage of the average wage in the formal sector. 2: The variable is rescaled as benchmark =100. 3: Ex-ante is the fiscal surplus of changing the policy parameter, all other things being equal (without any change in employment and wages). It is rescaled as benchmark $=100$.

We now investigate the fiscal cost of the reforms. We distinguish two measures of the fiscal cost: ex-ante and ex-post. The ex-ante measure represents the cost of the reform without any adjustment in employment or skill composition. This corresponds to a short-term evaluation of the cost of the 
reform. The ex-post measure includes all the aforementioned adjustments, thereby simulating a long run evaluation of the reform. As shown in Table 5 , the less costly reform ex-ante is the subsidy to education $(s)$ and the most costly is the decline in the payroll tax rate $\left(\tau_{f}\right)$. Indeed, before the reforms propagate to the labor market, the increase in $s$ lowers the fiscal surplus by $1.6 \%$, while the lower value of $\tau_{f}$ causes a $9.4 \%$ drop in the fiscal surplus. In the long run, subsidizing education raises the fiscal surplus by $3.7 \%$. On the contrary, despite the base on which the tax is levied increases significantly, lowering labor taxes causes the fiscal surplus to fall drastically by around $4.3 \%$. This raises the question of the sustainability of tax-based policies intended to reduce informality in developing countries. This critical issue is discussed in more detail in the next section.

Figure 6: Life-cycle effects of the policies

(a) Informality rate

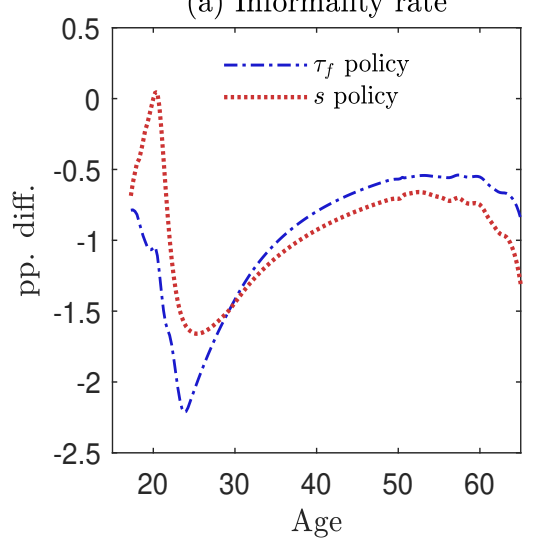

(d) Job separation rate

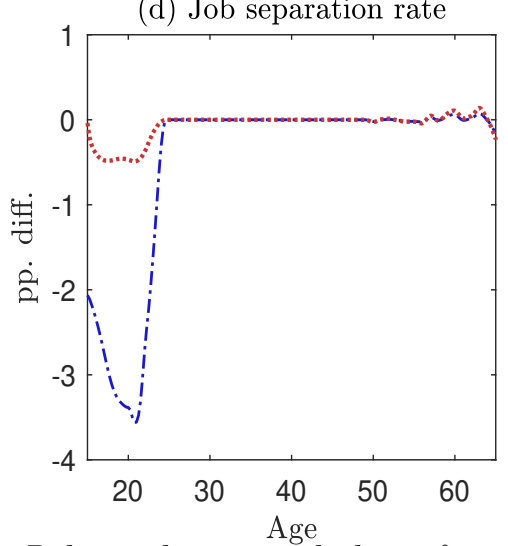

(b) Non employment rate

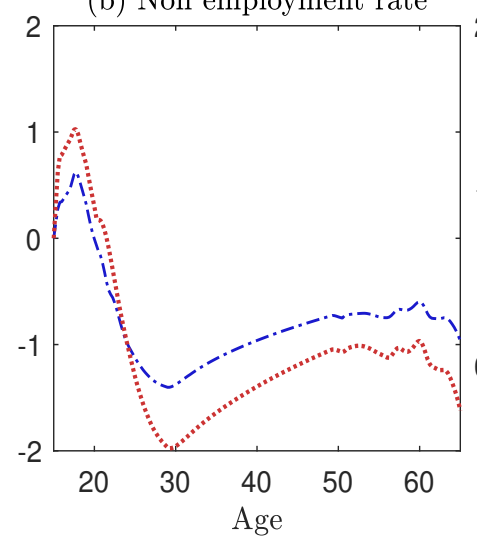

(e) Job finding rate

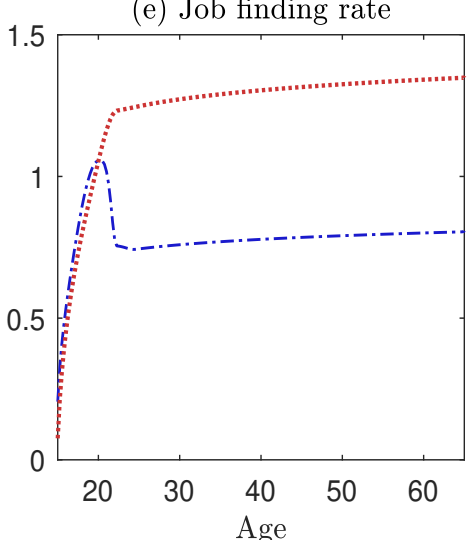

(c) Formal employment rate

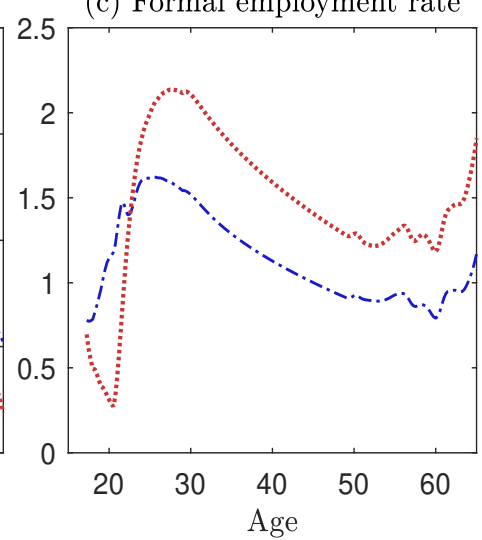

(f) Skill composition

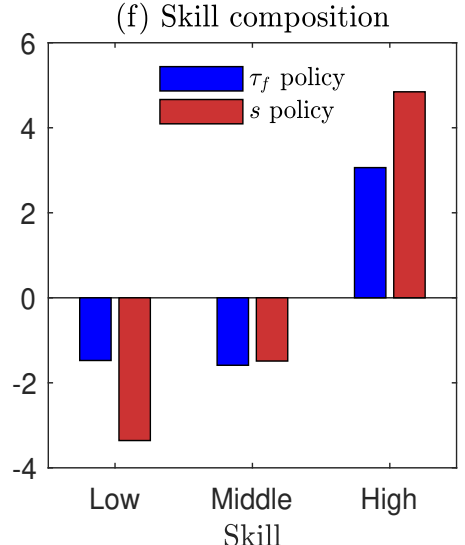

Policy achieving a decline of one percentage point of the aggregate informality rate. Values are expressed as percentage point changes with respect to the benchmark. 


\subsection{Varying the policy instrument}

A key issue among policymakers is the impact of the reform on government revenues. Tax-based reforms involve two opposite effects. On the one hand, when the tax rate is lower, a lower proportion of the worker's wage is collected by the government. On the other hand, as formal employment is higher, a larger proportion of the population pay taxes. This well-known trade-off is summarized by the Laffer curve that represents the levels of government revenue as a function of the rate of taxation. In our economy characterized by an important informal sector, what does this trade-off look like?

In this second experiment, we explore a broad range of values for taxes and subsidies (see Figure 7). Starting from the benchmark situation (red bullets), any tax decrease $\tau_{f}$ is likely to lower the fiscal surplus despite increasing formal employment. In the benchmark economy located on the rising part of the Laffer curve, improving the fiscal surplus is only feasible through an increase in taxes. Tax cuts are always detrimental to the budget because the base on which they are levied increases less rapidly than the tax decline. Beyond the peak of the Laffer curve located at $\tau_{f}=37.3 \%$, the fiscal surplus falls because of the strong decline in formal employment and lower incentive for individuals to study. Our results are consistent with those of Cruces et al. (2010), who evaluate the tax cuts in Argentina from the mid-1990s to the early 2000s. These tax cuts consisted of a reduction in the payroll tax from an almost uniform rate of $33 \%$ to between $6.6 \%$ and $23.1 \%$. The authors argue that the reform had a significant effect on government finance: payroll tax collection as a percentage of the total wage income (considering the whole country, but excluding the public sector and agricultural workers) almost halved.

On the contrary, subsidizing education can increase the fiscal surplus and lower informality and non-employment. From zero to $s *=60 \%$ of the average wage ${ }^{17}$, the subsidy generates a positive fiscal surplus. The employment and wage gains in the formal sector overcome the implementation costs of the subsidy. Further, the level of $s$ maximizing the fiscal surplus almost corresponds to the subsidy that generates the largest effects on informality and employment. The implementation of a subsidy of $22 \%$ of the average formal wage is sufficient to ensure that all individuals pursue higher education. Higher subsidy levels can achieve similar results in terms of informality and employment but are less advantageous with respect to the fiscal surplus.

\footnotetext{
${ }^{17}$ The reference corresponds to the formal average wage in the benchmark economy.
} 


\section{Figure 7: Alternative labor market policies}
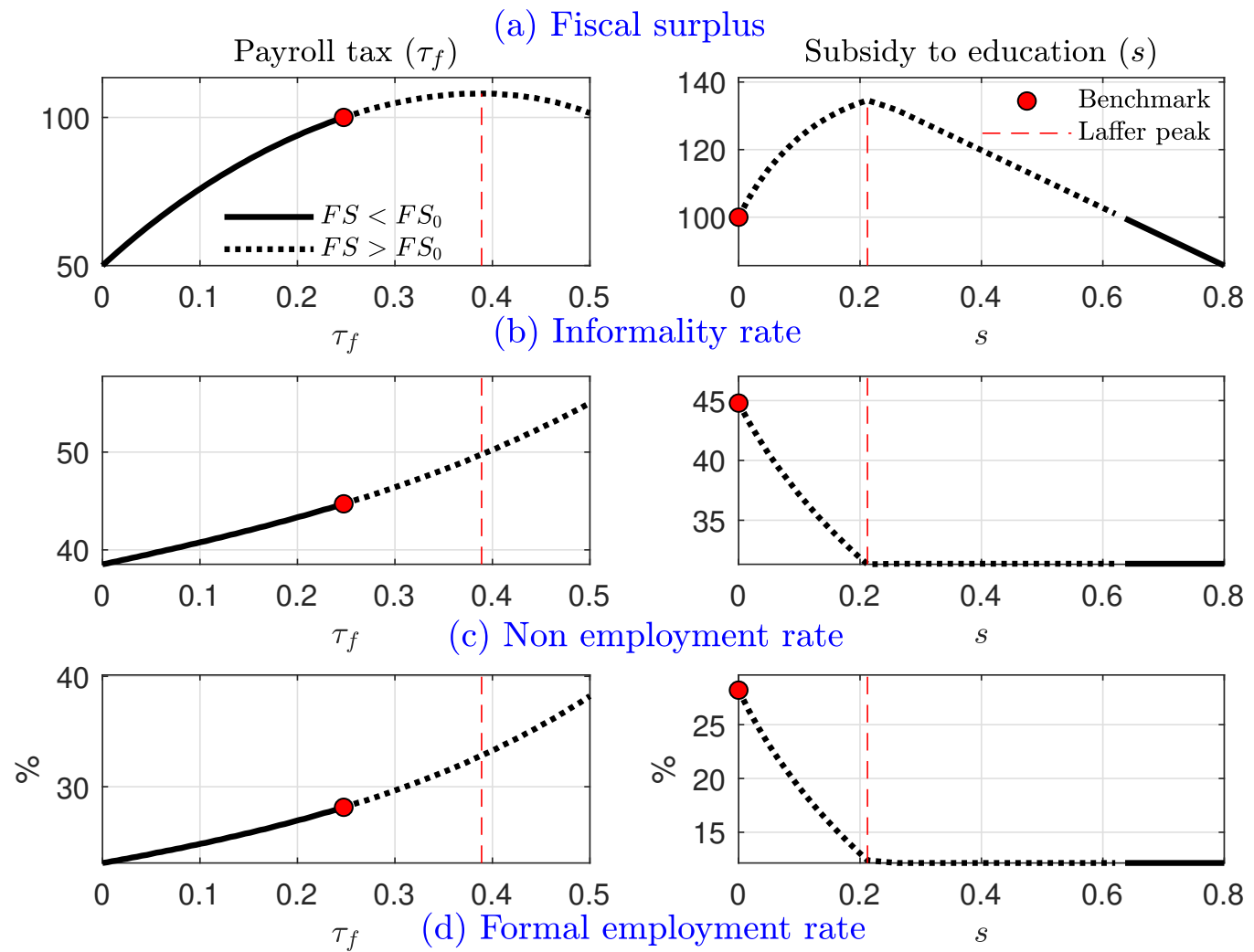

(d) Formal employment rate
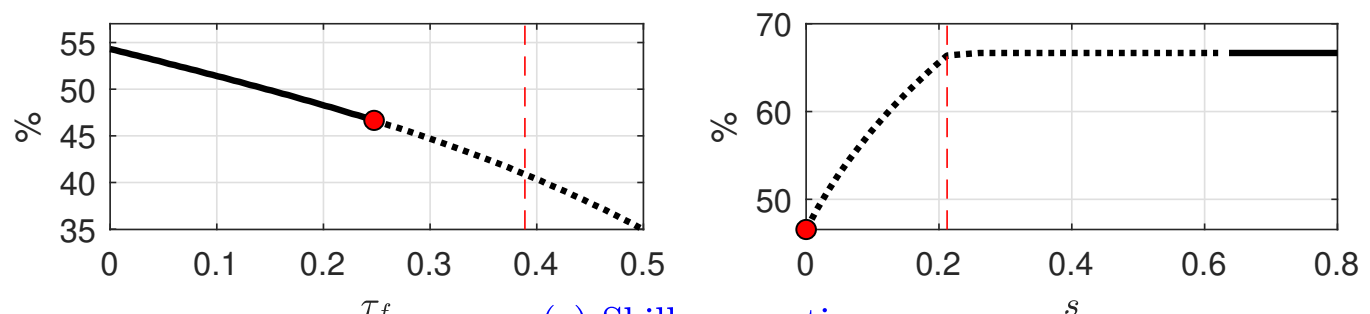

(e) Skill proportion
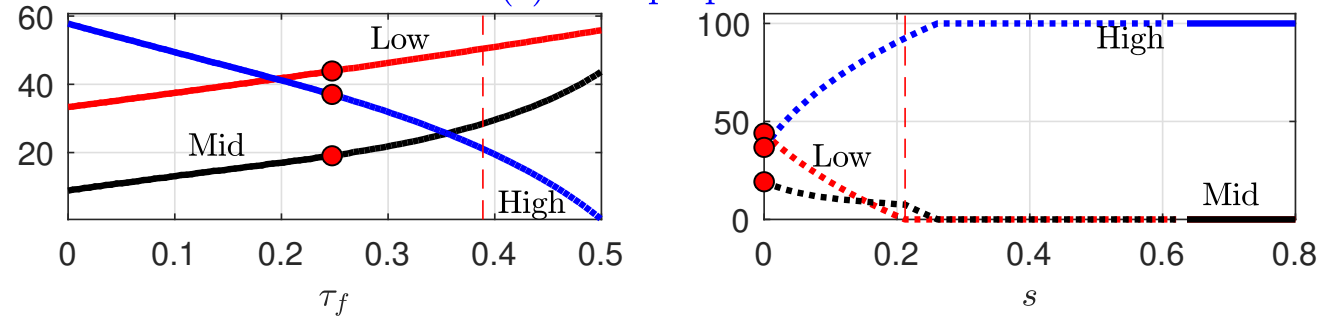

As shown previously, low-skilled workers are more likely to enter the informal sector or to rest unemployed than middle- and high-skilled workers. Several OECD countries have adopted structural tax reforms that aim to foster low-skilled employment by alleviating the tax burden on firms. 
In this line of policy recommendations, we consider a variation in the tax rate $\tau_{f}$ for low-skilled workers only. Figure 8 confirms that such a tax cut is unlikely to improve government revenues. While it has only mild negative effects on the fiscal surplus, the impact on informality is lower and so is the impact on formal employment and non-employment. These results arise from the change in the skills composition (Panel (e)). Indeed, tax cuts reduce the incentive for workers to study, which narrows the share of middle- and highskilled workers. This then results in a composition effect in which the higher non-employment rate of low-skilled workers accounts for a larger proportion of the aggregate non-employment rate. In turn, the change in educational attainment offsets the job creation effect at the aggregate level.

Figure 8: Tax cuts targeted to low-skilled workers

(a) Fiscal surplus

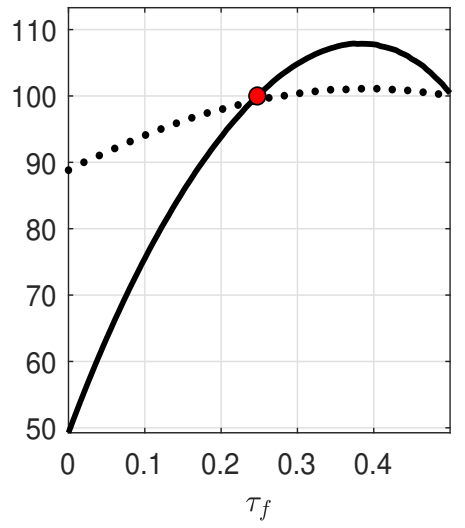

(d) Formal employment rate

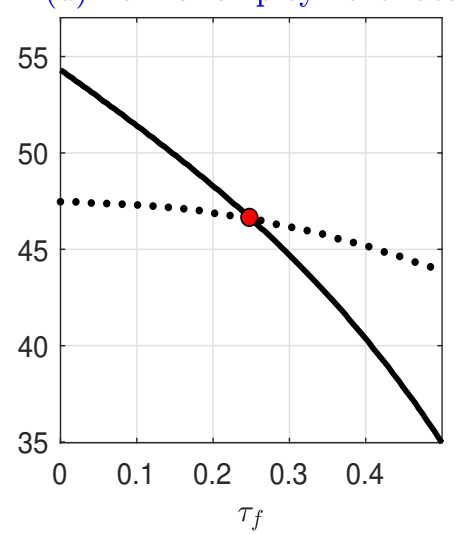

(b) Informality rate

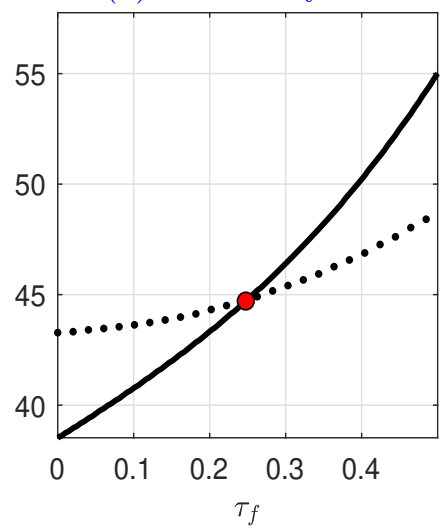

(e) Skill proportion

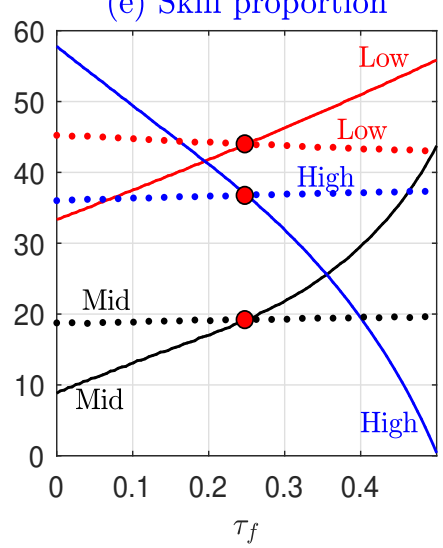

(c) Non employment rate

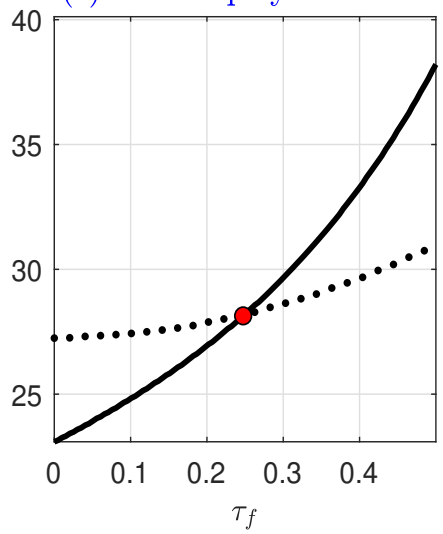

$\begin{array}{ll}\text { - } & \text { All workers } \\ \text { Low-skilled workers } & \text { Benchmark }\end{array}$

To summarize, the impact on government revenues is still negative; however, the reform is much less costly than when a tax reduction is applied to 
all job types. These results naturally raise the question of the sensitivity of education incentives with respect to labor taxes. This question is challenging and, to the best of our knowledge, remains a task for future research.

\subsection{Robustness of the results}

We check the robustness of the effects of the education subsidy. In particular, we focus on the public cost of education per student $(\Lambda)$. As stated before, considering the marginal public cost of education as equal to the average cost per student is a precautionary approach, and illustrates the upper bound of this cost. However, many studies have noted the existence of economies of scale in education, such that the marginal public cost of education may be significantly lower (Jimenez, 1986; Cohn et al., 1989; Dundar and Lewis, 1995; Koshal and Koshal, 1999; Toutkoushian and Lee, 2018). Since data on the marginal public cost in Argentina are lacking, we consider two scenarios that encompass the lower and upper bound effects of the subsidy-based reform:

- Scenario 1: Marginal public cost of education = Benchmark average public cost of education per student

- $\underline{\text { Scenario 2: }}$ Marginal public cost of education $=0$

The first scenario, dubbed "pessimistic," corresponds to the situation in which the marginal cost of education is equal to the average cost of education observed before the reform. This is the assumption used so far. In the second scenario, considered as "optimistic," the marginal cost of education is zero, meaning that the total cost of education remains unchanged, whatever the number of additional students. In that respect, we can properly evaluate the lower and upper bounds of the impact of the subsidy policy on the fiscal surplus. Figure 9 reports the results. In the most optimistic scenario, the range of the education subsidy $(s)$ over which the long run fiscal surplus is positive expands strongly. The maximum self-financed subsidy represents more than $70 \%$ of the average formal wage. However, as shown in Figure 7, the maximal effect of the policy can be reached for $s$ equal to $22 \%$ of the average formal wage. Such a subsidy raises the formal employment rate by almost 20 percentage points, while non-employment and informality decrease by 15 percentage points each. However, the consequences of such a policy on the fiscal surplus differ according to the scenario considered. In the first scenario, the policy implies a rise in the fiscal surplus of around $33 \%$. In the second scenario, the same policy increases the fiscal surplus by $45 \%$ at the peak of the Laffer curve. 
Figure 9: Fiscal surplus

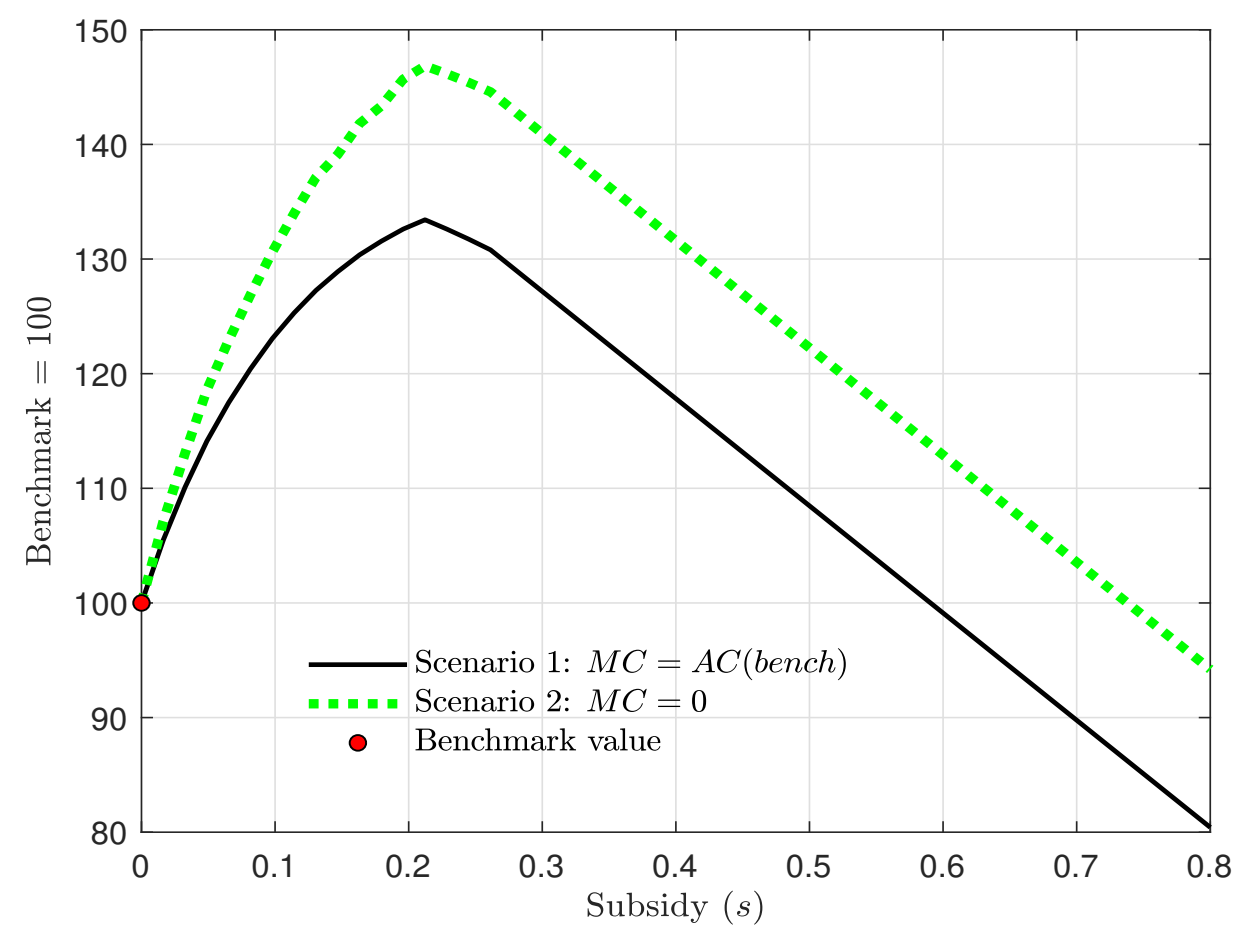

$M C$ stands for the marginal cost and $A C$ stands for the average cost.

\section{Conclusion and discussion}

This paper sheds new light on the dynamics of informality over the life-cycle. We propose a dual labor market theory that highlights how frictions and taxation in the formal sector and educational choices interact to explain the U-shape of the informality rate over the life-cycle. We develop a life-cycle model in which workers choose whether to run the risk to seek jobs in the frictional formal sector characterized by higher wages or accept instantaneously jobs in the competitive informal sector that offer lower wages. We estimate the structural model on Argentina data and show that it reproduces remarkably well the life-cycle patterns of the labor market stocks and flows, and wage differentials. Education decisions and frictions help explain the high informality rate observed among young people. On the other side of the age spectrum, workers close to the retirement age face a lower probability of finding a formal job and a higher risk of job destruction. As a consequence, they turn toward the informal sector to escape non-employment. 
In developing countries, informality has long been tolerated because of the conventional wisdom according to which there exists a trade-off between informality and employment. Indeed, there is strong empirical evidence showing that enforcement policies and repression of shadow activities reduce the size of the informal sector but the aggregate employment as well. However, this trade-off does not exist if we consider policies that increase the value of formal jobs instead of reducing the value of informal ones. To achieve this objective, several countries have resorted on product market deregulation reforms. However, such policies present some limitations. As highlighted by several studies (Uusitalo et al., 2002; Martuzzi et al., 2004; Hawkes, 2007; Brownell and Warner, 2009; Pelkmans, 2010), reducing product market regulation may induce negative social externalities and potential risks to the health and safety of consumers.

Tax reductions have also received favorable echoes. Numerous studies suggest lowering labor taxation to foster job creation and wages. However, most of the literature is muted on the fiscal costs of their policy recommendations. We tackle this issue and revisit the Laffer curve and show that reduction in the taxes, targeted to a specific category of jobs or not, leads to a net loss in tax revenues in the case of Argentina. Consequently, lowering taxes succeed in reducing informality but may have damaging consequences for the government budget.

We propose an alternative policy that consists in subsidizing education. The subsidy affects the skill composition of the labor force and reduces both informality and non-employment, without running government deficits. For reasonable subsidy rates, the effects on formal employment and wages overcome the extra public cost of education, which in turn generates a net gain in tax revenues. Education policies can lead to promising results in developing countries but also raise some important questions. In particular, what can we do for those that have already left school? We believe that further research about the role of lifelong training and human capital accumulation is needed. This is on our agenda. 


\section{References}

Albrecht, J., Navarro, L., \& Vroman, S. (2009). The effects of labour market policies in an economy with an informal sector. The Economic Journal, 119(539), 1105-1129.

Anand, R. \& Khera, P. (2016). Macroeconomic impact of product and labor market reforms on informality and unemployment in India. International Monetary Fund.

Bagger, J., Fontaine, F., Postel-Vinay, F., \& Robin, J.-M. (2014). Tenure, experience, human capital, and wages: A tractable equilibrium search model of wage dynamics. The American Economic Review, 104(6), 1551-1596.

Blundell, R., Costa Dias, M., Meghir, C., \& Shaw, J. (2016). Female labor supply, human capital, and welfare reform. Econometrica, 84(5), 17051753.

Boeri, T., Garibaldi, P., Hall, R. E., \& Pissarides, C. A. (2005). Shadow sorting. In NBER International Seminar on Macroeconomics (pp. 125170).: JSTOR.

Bosch, M. \& Esteban-Pretel, J. (2012). Job creation and job destruction in the presence of informal markets. Journal of Development Economics, 98(2), 270-286.

Bosch, M. \& Esteban-Pretel, J. (2015). The labor market effects of introducing unemployment benefits in an economy with high informality. European Economic Review, 75, 1-17.

Bosch, M. \& Maloney, W. F. (2010). Comparative analysis of labor market dynamics using markov processes: An application to informality. Labour Economics, 17(4), $621-631$.

Brownell, K. D. \& Warner, K. E. (2009). The perils of ignoring history: Big tobacco played dirty and millions died. how similar is big food? The Milbank Quarterly, 87(1), 259-294.

Burdett, K., Carrillo-Tudela, C., \& Coles, M. G. (2011). Human capital accumulation and labor market equilibrium. International Economic Review, $52(3), 657-677$.

Busso, M., Levy, S., Neumeyer, A., \& Spector, M. (2012). Skills, informality and the size distribution of firms. Buenos Aires, Argentina: Universidad Torcuato di Tella. 
Charlot, O., Malherbet, F., \& Terra, C. (2015). Informality in developing economies: Regulation and fiscal policies. Journal of Economic Dynamics and Control, 51, 1-27.

Chéron, A., Hairault, J.-O., \& Langot, F. (2013). Life-cycle equilibrium unemployment. Journal of Labor Economics, 31(4), 843-882.

Chéron, A. \& Terriau, A. (2018). Life cycle training and equilibrium unemployment. Labour Economics, 50, 32-44.

Cohn, E., Rhine, S. L., \& Santos, M. C. (1989). Institutions of higher education as multi-product firms: Economies of scale and scope. The Review of Economics and Statistics, (pp. 284-290).

Cruces, G., Galiani, S., \& Kidyba, S. (2010). Payroll taxes, wages and employment: Identification through policy changes. Labour Economics, 17(4), 743-749.

Dundar, H. \& Lewis, D. R. (1995). Departmental productivity in american universities: Economies of scale and scope. Economics of Education Review, 14(2), 119-144.

Fernández, C. \& Villar, L. (2017). The impact of lowering the payroll tax on informality in colombia. Economía, 18(1), 125-155.

Fields, G. S. (1975). Rural-urban migration, urban unemployment and underemployment, and job-search activity in ldcs. Journal of Development Economics, 2(2), 165-187.

Frenette, M. (2004). Access to college and university: Does distance to school matter? Canadian Public Policy/Analyse de Politiques, (pp. 427-443).

Frenette, M. (2006). Too far to go on? distance to school and university participation. Education Economics, 14(1), 31-58.

Garcia, I. (2015). Human capital and labor informality in chile: a life-cycle approach.

Garcia-Cicco, J., Pancrazi, R., \& Uribe, M. (2010). Real business cycles in emerging countries? American Economic Review, 100(5), 2510-31.

Harris, J. R. \& Todaro, M. P. (1970). Migration, unemployment and development: a two-sector analysis. The American Economic Review, 60(1), $126-142$. 
Hawkes, C. (2007). Regulating and litigating in the public interest: regulating food marketing to young people worldwide: trends and policy drivers. American Journal of Public Health, 97(11), 1962-1973.

Hopenhayn, H. (2004). Labor market policies and employment duration. the effects of labor market reform in argentina. In Law and Employment: Lessons from Latin America and the Caribbean (pp. 497-516). University of Chicago Press.

Iturriza, A., Bedi, A. S., \& Sparrow, R. (2011). Unemployment assistance and transition to employment in argentina. Economic Development and Cultural Change, 59(4), 811-837.

Jimenez, E. (1986). The structure of educational costs: multiproduct cost functions for primary and secondary schools in latin america. Economics of Education Review, 5(1), 25-39.

Koshal, R. K. \& Koshal, M. (1999). Economies of scale and scope in higher education: a case of comprehensive universities. Economics of Education Review, 18(2), 269-277.

La Porta, R. \& Shleifer, A. (2008). The unofficial economy and economic development. Technical report, National Bureau of Economic Research.

La Porta, R. \& Shleifer, A. (2014). Informality and development. Journal of Economic Perspectives, 28(3), 109-26.

Lewis, W. A. (1954). Economic development with unlimited supplies of labour. The Manchester School, 22(2), 139-191.

Maloney, W. F. (1999). Does informality imply segmentation in urban labor markets? evidence from sectoral transitions in mexico. The World Bank Economic Review, 13(2), 275-302.

Martuzzi, M., Tickner, J. A., et al. (2004). The precautionary principle: protecting public health, the environment and the future of our children.

Meghir, C., Narita, R., \& Robin, J.-M. (2015). Wages and informality in developing countries. American Economic Review, 105(4), 1509-46.

Menzio, G., Telyukova, I. A., \& Visschers, L. (2016). Directed search over the life cycle. Review of Economic Dynamics, 19, 38-62.

Munkacsi, Z. \& Saxegaard, M. M. (2017). Structural Reform Packages, Sequencing, and the Informal Economy. International Monetary Fund. 
Narita, R. (2011). Self employment in developing countries: a searchequilibrium approach. The World Bank.

OECD/CIAT/IDB (2016). Taxing wages in latin america and the caribbean. OECD Publishing, Paris.

Pelkmans, J. (2010). Product market reforms in eu countries: Are the methodology and evidence sufficiently robust?

Rocha, R., Ulyssea, G., \& Rachter, L. (2018). Do lower taxes reduce informality? evidence from brazil. Journal of Development Economics, 134, $28-49$

Rotemberg, J. J. (2008). Cyclical Wages in a Search-and-Bargaining Model with Large Firms. In NBER International Seminar on Macroeconomics 2006, NBER Chapters (pp. 65-114). National Bureau of Economic Research, Inc.

Satchi, M. \& Temple, J. (2009). Labor markets and productivity in developing countries. Review of Economic Dynamics, 12(1), 183-204.

Schneider, F. \& Enste, D. H. (2000). Shadow economies: size, causes, and consequences. Journal of Economic Literature, 38(1), 77-114.

Todaro, M. P. (1969). A model of labor migration and urban unemployment in less developed countries. The American Economic Review, 59(1), 138148.

Toutkoushian, R. K. \& Lee, J. C. (2018). Revisiting economies of scale and scope in higher education. In Higher Education: Handbook of Theory and Research (pp. 371-416). Springer.

Ulyssea, G. (2010). Regulation of entry, labor market institutions and the informal sector. Journal of Development Economics, 91(1), 87-99.

Uusitalo, U., Pietinen, P., \& Puska, P. (2002). Dietary transition in developing countries: challenges for chronic disease prevention. Globalization, Diets and Non-communicable Diseases, 1, 25.

Zenou, Y. (2008). Job search and mobility in developing countries. theory and policy implications. Journal of Development Economics, 86(2), 336-355. 


\section{A Logit model for informal employment}

\begin{tabular}{lcc}
\hline & Coefficient & Standard error \\
\hline Age & $-0.1861^{* * *}$ & 0.0020 \\
Age squared & $0.0019^{* * *}$ & 0.0001 \\
Male & $-0.6679^{* * *}$ & 0.0073 \\
Low education & $1.1617^{* * *}$ & 0.0086 \\
High education & $-0.6831^{* * *}$ & 0.0096 \\
Couple & $-0.4592^{* * *}$ & 0.0075 \\
\hline Region of residence & & \\
$\quad$ Gran Buenos Aires & $-0.2481^{* * *}$ & 0.0140 \\
$\quad$ NOA & $0.2130^{* * *}$ & 0.0134 \\
$\quad$ NEA & $0.1515^{* * *}$ & 0.0151 \\
$\quad$ Pampeana & $-0.2522^{* * *}$ & 0.0127 \\
Patagonica & $-1.0150^{* * *}$ & 0.0148 \\
\hline Constant & 3.9294 & 0.0392 \\
\hline Solice: EPH $2008-2014$ & &
\end{tabular}

Source: EPH 2008-2014

Note: $*$ implies a significant coefficient at $10 \%, * *$ at $5 \%$, and $* * *$ at $1 \%$

Sample: Individuals aged $16-65$ years

Number of observations: 337,979

\section{B Skill categories}

\begin{tabular}{lc}
\hline Skill & Education level \\
\hline Low-skilled workers & Incomplete primary (includes special education) \\
Complete primary
\end{tabular}




\section{Entries and exits in the labor market}
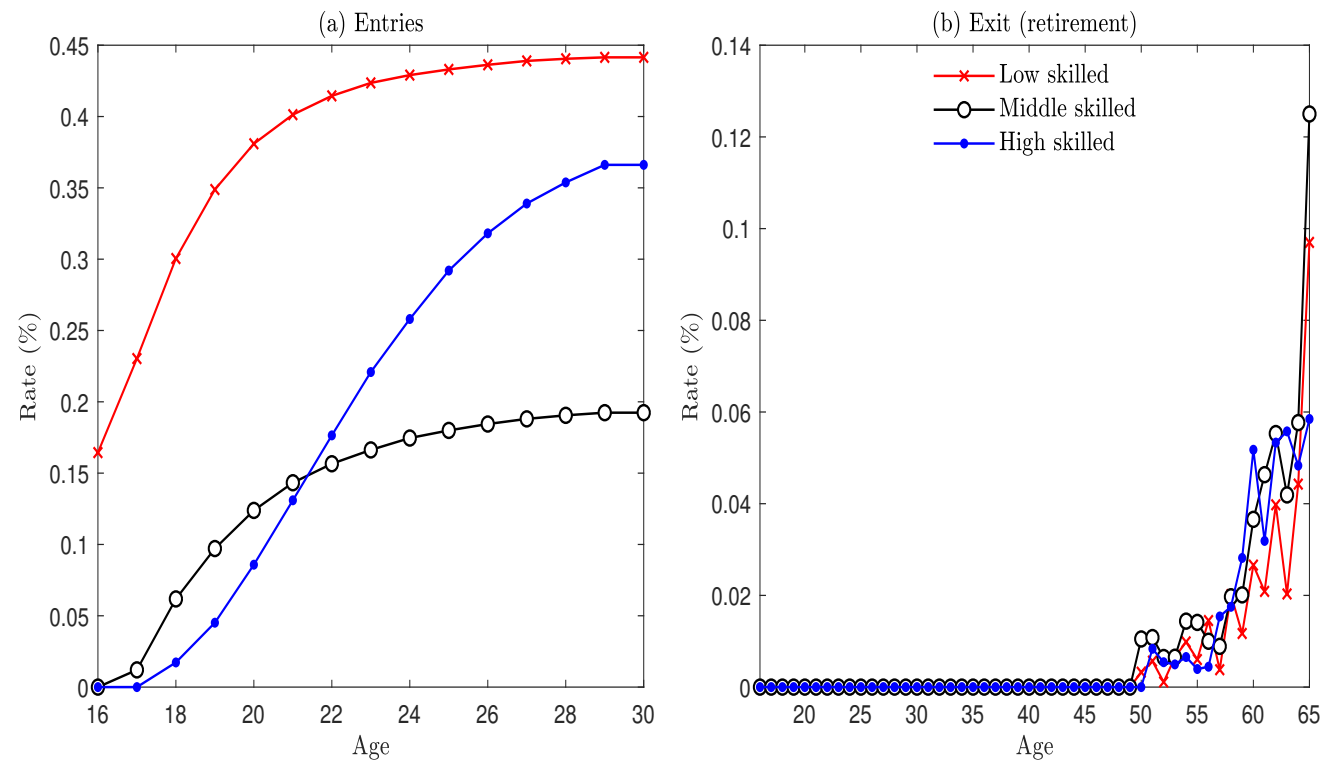

\section{Labor taxation}

\begin{tabular}{lccc}
\hline Contribution & $\begin{array}{c}\text { Employers (\%) } \\
\text { (commerce } \\
\text { (and services) }\end{array}$ & $\begin{array}{c}\text { Employers (\%) } \\
\text { (other activities) }\end{array}$ & Employees (\%) \\
\hline Pension fund & 10.17 & 12.71 & 11.00 \\
Family allowance fund & 5.33 & 6.67 & - \\
Social health & 6.00 & 6.00 & 3.00 \\
Social services & 1.50 & 1.62 & 3.00 \\
\hline Total & $\mathbf{2 3 . 0 0}$ & $\mathbf{2 7 . 0 0}$ & $\mathbf{1 7 . 0 0}$ \\
\hline
\end{tabular}

Source: Argentine Ministry of Labor 